\title{
ANÁLISE DA PRODUÇÃO CIENTÍFICA SOBRE ARRANJOS PRODUTIVOS LOCAIS NOS PRINCIPAIS PERIÓDICOS NACIONAIS DE ENGENHARIA DE PRODUÇÃO
}

\section{ANALYSIS OF THE SCIENTIFIC LITERATURE ABOUT LOCAL PRODUCTION NETWORKS IN THE BRAZILIAN TOP JOURNALS OF PRODUCTION ENGINEERING}

\author{
Cláudia Fabiana Gohr ${ }^{1}$; Rodrigo Araújo de Medeiros ${ }^{2}$; Luciano Costa Santos ${ }^{3}$ \\ ${ }^{1}$ Universidade Federal da Paraíba - UFPB - João Pessoa/PB - Brasil \\ claudiagohr@ct.ufpb.br \\ ${ }^{2}$ Universidade Federal da Paraíba - UFPB - João Pessoa/PB - Brasil \\ rodrigoamedeiros@gmail.com \\ ${ }^{3}$ Universidade Federal da Paraíba - UFPB - João Pessoa/PB - Brasil \\ luciano@ct.ufp
}

\section{Resumo}

Este artigo tem como principal objetivo desenvolver um levantamento da produção científica sobre arranjos produtivos locais nos principais periódicos nacionais da área de Engenharia de Produção, apresentando uma perspectiva sobre os estudos feitos e os principais assuntos pesquisados nos últimos onze anos. $O$ artigo adotou a abordagem de revisão sistemática de literatura que foi utilizada com a finalidade de desenvolver um levantamento da produção científica sobre arranjos produtivos locais em sete periódicos nacionais da área de Engenharia de Produção. A escolha dos periódicos se deu em função destes serem classificados no sistema de avaliação de CAPES (QUALIS) na área de Engenharias III, que engloba a Engenharia de Produção. A busca de artigos utilizou como base as palavras-chave: "arranjos produtivos locais" ou "arranjo produtivo". Em uma pesquisa inicial foram encontrados 93 artigos, dos quais 64 foram descartados de acordo com os critérios de exclusão estabelecidos. Foram analisados 29 artigos em função dos seguintes aspectos: evolução das publicações; tipo de APL pesquisado; definições de APL; procedimento de pesquisa; procedência dos autores dos artigos; região e instituição; contribuições por autor; contribuições por periódico; e, abordagem teórica adotada nos artigos. Por meio da análise, pôde-se concluir que a pesquisa sobre a temática está em evolução, embora ainda seja observada uma escassez de trabalhos em grande parte das áreas da Engenharia de Produção definidas pela ABEPRO.

Palavras-chave: arranjos produtivos locais; revisão sistemática; periódicos nacionais.

\section{Introdução}

A globalização da economia e o crescimento da complexidade no âmbito competitivo fizeram com que as empresas buscassem por novos formatos empresariais, maiores vantagens frente à concorrência, bem como maiores rendimentos. É nesse contexto que surge o conceito de arranjos empresariais ou redes de empresas, que apareceram como uma forma de alavancar a vantagem 
competitiva das empresas, devido aos resultados do compartilhamento de recursos e capacidades, colaboração, complementaridade, entre outros aspectos.

As redes empresariais podem ser definidas em função de três aspectos: os "nós" que compõem a rede, os laços que conectam os "nós" e os padrões ou estruturas que resultarem de tais ligações (AHUJA; SODA; ZAHEER, 2012). A formação de redes empresariais gera maiores possibilidades na superação de entraves ao crescimento econômico, pois de acordo com Marchi e Wittmann (2008) as redes de empresas envolvem organizações independentes; coopetividade (cooperação com competitividade); comprometimento, confiança; relações de troca; e, criação de valor.

O tema arranjos empresariais tem recebido atenção de pesquisadores nacionais e internacionais recentemente. No âmbito internacional, por exemplo, Lin et al (2011) estudaram como as fábricas de equipamentos originais (OEM) têm crescido por meio da formação de clusters industriais e de alianças estratégicas. Arıkan e Schilling (2011), por sua vez, demonstraram os custos e as vantagens competitivas oriundas dos distritos industriais, pois para eles as pesquisas até então são fragmentadas e trazem resultados conflitantes para os gestores. Já Andersson e Lööf (2011) promoveram um estudo com as empresas da Suécia para verificar se a aglomeração produtiva de empresas realmente estimula a produtividade das organizações. Em outro estudo, Alcácer e Zhao (2012) verificaram de que forma as empresas participantes de um cluster altamente competitivo podem desenvolver e manter relações internas e compartilhamento de conhecimento no departamento de pesquisa e desenvolvimento.

De acordo com Andersson e Lööf (2011), muitas empresas atuam em aglomeradas em uma mesma região territorial devido ao fato dessas aglomerações proporcionarem vantagens, pois a interação entre as sinergias coletivas e o ambiente podem permitir melhores oportunidades de crescimento e sobrevivência para essas organizações. Dessa forma, um dos formatos de redes empresariais que tem se destacado são os chamados Arranjos Produtivos Locais (APL's). Um APL, de acordo com Suzigan (2006), pode ser definido, como um sistema de agentes econômicos, políticos e sociais que possuem vínculos entre si (sejam produtivos e/ou institucionais) de forma a gerar aos agentes um conjunto de benefícios relacionados com a aglomeração das empresas.

As redes de cooperação têm sido um assunto em pauta tanto de pesquisadores como dos governos em vários países, sejam eles desenvolvidos ou emergentes, principalmente em função dos resultados bem sucedidos da Terceira Itália a partir da década de 1970; dos sistemas produtivos locais na França, Alemanha e Reino Unido; da experiência do Vale do Silício nos EUA, das redes de empresas no Japão (keiretsu), Coréia (chaebol) e Taiwan (guanxi); e dos conceitos apresentados por Michael Porter na década de 1990 sobre os determinantes da vantagem competitiva nacional (GEROLAMO et al, 2008; REIS e AMATO NETO, 2012; CASAROTTO FILHO, 2002). 
Em se tratando de Brasil, o termo APL passou a ser difundido principalmente a partir da década de 1990 (SACOMANO NETO e PAULILLO, 2012). Em um levantamento realizado por Suzigan (2006) em que foram identificados, mapeados e caracterizados os arranjos produtivos locais no Brasil, foram levantados 762 com base nos resultados da RAIS (Relação Anual de Informações Sociais, elaborada pelo Governo Federal) no ano de 2004.

Os impactos dos APL's nas economias, assim como o interesse em se pesquisar esses impactos, tanto em empresas como nas regiões em que eles estão inseridas, fizeram com que houvesse um maior interesse acerca do tema, o que permitiu que muitas pesquisas fossem desenvolvidas no âmbito acadêmico e governamental, principalmente pela importância que esse tipo de aglomeração vem ganhando para o desenvolvimento econômico e social. Dentro da Engenharia de Produção (EP) esta temática também tem recebido atenção, conforme se pode observar no aumento das pesquisas nos últimos anos, como se verifica nos trabalhos de Souza e Arica (2006a), Galdámez, Carpinetti e Gerolamo (2009), Santos e Batalha (2010), Petter, Resende e Ceranto (2011a,b), entre outras que serão apresentadas neste artigo e que tinham como foco diferentes arranjos produtivos.

Dessa forma, o presente artigo propõe-se a contribuir par a compreensão do tema, pois tem como principal objetivo desenvolver um levantamento da produção científica sobre arranjos produtivos locais nos principais periódicos nacionais da área de Engenharia de Produção nos últimos onze anos, apresentando uma perspectiva sobre os estudos feitos e os principais assuntos pesquisados.

Os Arranjos Produtivos são um tema de interesse da Engenharia de Produção, pois se trata de um tema transversal e que pode ser estudado segundo as diferentes áreas da EP definidas pela ABEPRO (2013). Recentemente, Gonçalves, Leite e Silva (2012) desenvolveram um estudo preliminar sobre as definições e as diferenças dos principais tipos de arranjos empresariais, dada a ampla e controversa literatura sobre a área. Já Cardoso, Cardoso e Casarotto Filho (2011) fizeram uma análise sobre as pesquisas sobre arranjos produtivos nos periódicos da Associação Brasileira de Engenharia de Produção (ABEPRO), nos Anais do ENEGEP e nos Anais do International Conference on Industrial Engineering and Operations Management (ICIEOM) referente ao período de 2005 a 2009, detalhando a análise nos anos de 2008 e 2009.

A pesquisa deste artigo foi desenvolvida utilizando como base as seguintes palavras-chave: “Arranjo Produtivo Local” ou "Arranjo Produtivo". Os periódicos consultados foram: Produção, Gestão \& Produção, Produção Online, Revista Gestão Industrial, Revista GEPROS, Sistemas \& Gestão e Produto \& Produção, totalizando 07 periódicos. Uma das contribuições deste artigo é apresentar assuntos de pesquisa na área que ainda precisam ser explorados dentro do contexto da Engenharia de Produção, servindo de base para futuras pesquisas. Outra contribuição é sintetizar os 
principais resultados encontrados nas pesquisas desenvolvidas dentro do contexto da Engenharia de Produção.

$\mathrm{O}$ artigo encontra-se estruturado da seguinte forma. Primeiramente é desenvolvida uma revisão teórica sobre a temática, ressaltando a importância dos arranjos produtivos locais. Posteriormente, os procedimentos metodológicos são detalhados, para em seguida os resultados da pesquisa desenvolvida nos periódicos serem apresentados, seguidos das perspectivas futuras sobre arranjos produtivos para a Engenharia de Produção e das conclusões do trabalho.

\section{Arranjos produtivos locais}

As redes empresariais podem ser consideradas uma fonte relevante de vantagens competitivas, à medida que a interação entre as sinergias coletivas e o ambiente permitem melhores oportunidades de crescimento e sobrevivência.

A literatura de área e a terminologia relacionada às redes empresariais e, em especial, às aglomerações produtivas, são consideradas confusa e controversa, possuindo uma ampla variedade de conceitos e tipos (SACOMANO NETO e PAULILLO, 2012; GONÇALVES; LEITE; SILVA, 2012; SUZIGAN, 2006). De acordo com Suzigan (2006), as diferenças conceituais na literatura sobre aglomerações estão relacionadas a graus variados de desenvolvimento, de integração da cadeia produtiva, de articulação e interação entre agentes e instituições locais e de capacidades sistêmicas no que diz respeito à inovação. Dentre os principais tipos de aglomerações produtivas presentes na literatura, podem ser citados os condomínios industriais, os clusters, as cadeias de suprimento, os consórcios modulares, os arranjos produtivos locais, entre outros (BRITO e LEITE, 2008). Apesar de cada tipo de aglomeração produtiva possuir definições distintas, elas se complementam, pois existem características que são comuns entre elas e outras que são excludentes, conforme pode ser observado no Quadro 1 ilustrado a seguir.

Quadro 1 - Comparativo das características das aglomerações produtivas.

\begin{tabular}{|c|c|c|c|c|c|}
\hline 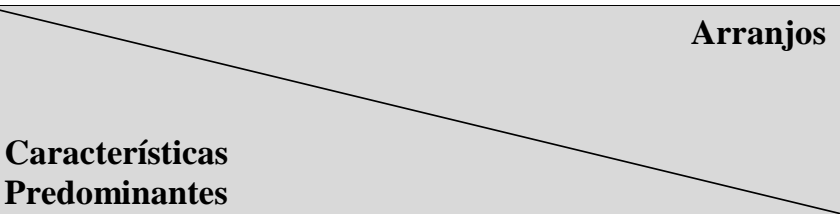 & 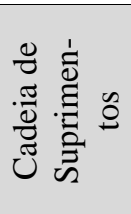 & 栉 & 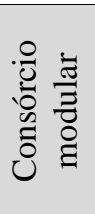 & $\frac{\bar{s}}{\frac{5}{0}}$ & $\overrightarrow{\frac{\alpha}{2}}$ \\
\hline Proximidade geográfica & & $\mathrm{X}$ & $\mathrm{X}$ & $\mathrm{X}$ & $\mathrm{X}$ \\
\hline Cooperação & $\mathrm{X}$ & & & $\mathrm{X}$ & $\mathrm{X}$ \\
\hline Competição & & & & $\mathrm{X}$ & \\
\hline Apoio de instituições de suporte & & & & $\mathrm{X}$ & \\
\hline Fornecedores realizando etapas do processo produtivo & & & $\mathrm{X}$ & & \\
\hline Fornecedores localizados próximos à empresa & & $\mathrm{X}$ & $\mathrm{X}$ & & \\
\hline Fornecedores localizados próximos ao arranjo & & & & $\mathrm{X}$ & \\
\hline Abrangência: fornecedores-cliente final & $\mathrm{X}$ & & & & \\
\hline
\end{tabular}

Fonte: Baseado em Brito e Leite (2008) 
Um dos formatos de redes empresariais que tem se destacado são os chamados Arranjos Produtivos Locais (APL's). Existe na literatura uma variedade de definições sobre APL's, segundo diferentes autores, órgãos ou entidades de pesquisa, conforme pode ser verificado no Quadro 2.

Nas aglomerações produtivas é de fundamental importância a concentração geográfica das atividades, pois esta apresenta vantagens externas às empresas e internas às aglomerações que são formadas (PORTER, 1990; ANDERSSON e LÖÖF, 2011), assim como a cooperação entre as empresas (BRITO e LEITE, 2008; GONÇALVES; LEITE; SILVA, 2012). Além disso, no âmbito macroeconômico, os aglomerados possibilitam investimentos consideráveis do setor privado que aumentam o número de empregos (VIAL et al, 2009) e auxiliam no processo de desenvolvimento econômico e social local (ARIKAN e SCHILLING, 2011). No âmbito microeconômico, ou seja, para as empresas, as aglomerações produtivas permitem o compartilhamento e a criação de recursos e de conhecimentos, a redução de custos de transação e a facilidade no processo de inovação, proporcionando o desenvolvimento de vantagens competitivas para as empresas que fazem parte do aglomerado (CHAI; YAP; WANG, 2011; ARIKAN; SCHILLING, 2011; ALCÁCER; ZHAO, 2012).

Quadro 2 - Definições de arranjos produtivos locais (APL's)

\begin{tabular}{|c|c|}
\hline Instituição/Autor & Definição \\
\hline $\begin{array}{l}\text { Cassiolato e Lastres } \\
\quad(2003 \text {, p. } 3-4)\end{array}$ & $\begin{array}{l}\text { São aglomerações territoriais de agentes econômicos, políticos e sociais - com foco em } \\
\text { um conjunto específico de atividades econômicas - que apresentam vínculos mesmo que } \\
\text { incipientes. Geralmente envolvem a participação e a interação de empresas - que podem } \\
\text { ser desde produtoras de bens e serviços finais até fornecedoras de insumos e } \\
\text { equipamentos, prestadoras de consultoria e serviços, comercializadoras, clientes, entre } \\
\text { outros - e suas variadas formas de representação e associação. Incluem também diversas } \\
\text { outras organizações públicas e privadas voltadas para: formação e capacitação de } \\
\text { recursos humanos, como escolas técnicas e universidades; pesquisa, desenvolvimento e } \\
\text { engenharia; política, promoção e financiamento. }\end{array}$ \\
\hline Casarotto Filho (2002) & $\begin{array}{l}\text { Um sistema produtivo local são redes de cooperação de negócios, caracterizados pela } \\
\text { concentração territorial, pela especialização em torno de um produto e pela solidariedade } \\
\text { entre os atores. }\end{array}$ \\
\hline Amato Neto (2000) & $\begin{array}{l}\text { Um APL acumula vários tipos de conhecimento, que podem ser repartidos entre as } \\
\text { empresas constituintes do arranjo. Tal característica se dá em virtude dos } \\
\text { relacionamentos pessoais e os laços que existem na comunidade permitirem uma maior } \\
\text { confiança e facilitação do fluxo de informações. }\end{array}$ \\
\hline BNDES (2000) & $\begin{array}{l}\text { A principal característica é o elo de pequenas e médias empresas que estão concentradas } \\
\text { em um mesmo espaço, gerando, dessa maneira, a cooperação entre as mesmas e, } \\
\text { consequente, ganho produtivo e econômico. Isso pode evidenciado a partir de uma das } \\
\text { inúmeras definições atribuídas aos APL's. }\end{array}$ \\
\hline Suzigan (2006, p.3) & $\begin{array}{l}\text { É um sistema localizado de agentes econômicos, políticos e sociais ligados a um mesmo } \\
\text { setor ou atividade econômica, que possuem vínculos produtivos e institucionais entre si, } \\
\text { de modo a proporcionar aos produtores um conjunto de benefícios relacionados com a } \\
\text { aglomeração das empresas. Configura-se um sistema complexo em que operam diversos } \\
\text { subsistemas de produção, logística e distribuição, comercialização, desenvolvimento } \\
\text { tecnológico (P\&D, laboratórios de pesquisa, centros de prestação de serviços } \\
\text { tecnológicos) e onde os fatores econômicos, sociais e institucionais estão fortemente } \\
\text { entrelaçados. }\end{array}$ \\
\hline
\end{tabular}

Fonte: Elaborado pelos autores 
Para Borin (2006), um arranjo produtivo bem estruturado e saudável deve possuir elementos estruturantes que são fundamentais, tais como: a cooperação, a coordenação institucional, a aprendizagem, a inovação, a competitividade e o território; embora a cooperação seja um dos grandes diferenciais do conceito de APL em relação aos demais aglomerados produtivos (exceto as cadeias de suprimentos e os clusters).

De acordo com Reis e Amato Neto (2012), além da cooperação, a confiança é outro aspecto fundamental para que o arranjo obtenha ganhos econômicos. Por meio da confiança, reduz-se o grau de oportunismo e a quebra de contratos que geram perdas não apenas para os empresários, mas para a própria comunidade local, pois se deixa de obter ganhos por meio de externalidades positivas oriundas da aglomeração produtiva de empresas.

Analisando a literatura sobre redes empresariais e, em especial, sobre arranjos produtivos, pode-se constatar um conjunto de perspectivas teóricas que consideram alguns fundamentos sobre o processo de cooperação e parceria entre as empresas, tais como a teoria dos jogos, a teoria dos custos de transação, a teoria das redes sociais, a teoria da aprendizagem, a teoria baseada em recursos, entre outras (LAVIE, 2006; VALE e LOPES, 2010; WILK, 2006). De acordo com Vale e Lopes (2010), cada uma das diferentes perspectivas teóricas apresenta um conjunto específico de premissas e concepções acerca do processo de cooperação entre empresas, conforme pode ser observado no Quadro 3. Na próxima seção serão apresentados os procedimentos metodológicos que nortearam o desenvolvimento da presente pesquisa.

Quadro 3 - Perspectivas teóricas que estudam processos de parceria e cooperação entre empresas

\begin{tabular}{|l|l|}
\hline Perspectivas teóricas & \multicolumn{1}{|c|}{ Parceria/Cooperação } \\
\hline Teoria dos jogos & $\begin{array}{l}\text { Parceria resultante de experimentação e aprendizado, evitando dilema dos prisioneiros e } \\
\text { permitindo otimizar benefícios mútuos. }\end{array}$ \\
\hline Poder de mercado & $\begin{array}{l}\text { Parcerias, no contexto de uma cadeia produtiva, um grupo empresarial ou região, como } \\
\text { forma de incrementar o poder de mercado. }\end{array}$ \\
\hline Custos de transação & O recurso às parcerias como estratégia de redução dos custos de transação. \\
\hline Redes sociais & $\begin{array}{l}\text { O lado invisível das alianças e estratégias empresariais, condicionadas e influenciadas pela } \\
\text { lógica das redes sociais. }\end{array}$ \\
\hline $\begin{array}{l}\text { Visão baseada em } \\
\text { recursos }\end{array}$ & $\begin{array}{l}\text { Papel dos recursos, seu compartilhamento e criação de novos recursos de forma a criar } \\
\text { vantagens competitivas sustentáveis na rede. }\end{array}$ \\
\hline $\begin{array}{l}\text { Gestão do conhecimento } \\
\text { Socialização, externalização, combinação e internalização do conhecimento entre } \\
\text { empresas do arranjo empresarial. }\end{array}$ \\
\hline $\begin{array}{l}\text { Aprendizagem } \\
\text { organizacional }\end{array}$ & $\begin{array}{l}\text { A importância da interação e do compartilhamento de conhecimentos entre empresas na } \\
\text { competitividade empresarial. }\end{array}$ \\
\hline
\end{tabular}

Fonte: Elaborado pelos autores e baseado em Vale e Lopes (2010) e Wilk (2006)

\section{Procedimentos metodológicos}

Este trabalho utilizou a abordagem de revisão sistemática de literatura, que foi utilizada com a finalidade de desenvolver um levantamento da produção científica sobre arranjos produtivos 
locais nos principais periódicos nacionais da área de Engenharia de Produção nos últimos onze anos.

As revisões sistemáticas se propõem a classificar e quantificar as contribuições científicas na área que é objeto de estudo, assim como consolidar os resultados por meio dos estudos realizados (CARLSON e JI, 2011). Recentemente este tipo de pesquisa tem crescido, tanto no país quanto no exterior, conforme pode ser verificado pelo aumento do número de publicações nacionais e internacionais que adotam esta abordagem de pesquisa. Uma revisão sistemática identifica as contribuições científicas chaves em um determinado campo de pesquisa, sendo considerada na atualidade uma atividade científica fundamental (TRANFIELD; DENYER; SMART, 2003).

A pesquisa foi desenvolvida tomando como base as seguintes palavras-chave: "Arranjos Produtivos Locais" ou “Arranjo Produtivo". Os periódicos consultados foram: Produção, Gestão \& Produção, Produção Online, Revista Gestão Industrial, Revista GEPROS, Sistemas \& Gestão e Produto \& Produção, totalizando 07 periódicos nacionais. O estudo foi feito nestes periódicos por estarem classificados no sistema de avaliação CAPES (QUALIS) na área de Engenharias III, que engloba a Engenharia de Produção.

O período de compreendeu a pesquisa foi de 01/01/2002 a 12/12/2012. Tais aspectos podem ser visualizados de forma detalhada na Figura 1. As palavras-chave deveriam aparecer no título e/ou no resumo e/ou nas palavras-chave dos artigos pesquisados sendo utilizadas as ferramentas de busca disponíveis no próprio site das revistas. Em alguns periódicos foi necessário acessar os sumários da revista, para fazer uma análise final em relação aos artigos que seriam selecionados para a pesquisa.

Figura 1 - Procedimentos de pesquisa adotados na revisão sistemática sobre APL’s

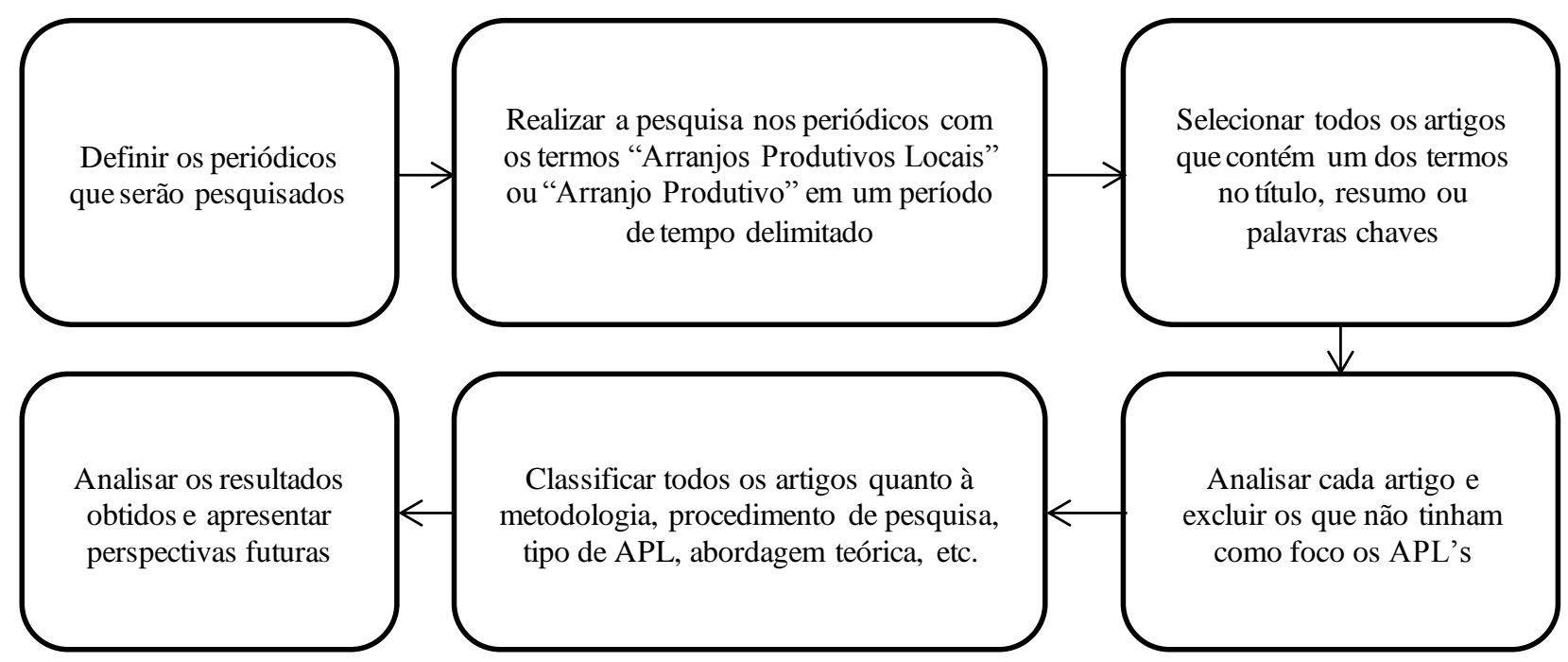

Fonte: Elaborado pelos autores

De acordo com o exposto na Figura 1, em uma pesquisa inicial, foram encontrados 93 artigos. Como primeiro critério de corte, foi feita uma análise se as palavras "Arranjo Produtivo" e 
“Arranjos Produtivos Locais" apareciam no título, resumo e palavras-chave, pois as ferramentas de busca não eram tão precisas, resultando na exclusão de 58 artigos dos 93 iniciais. Dentre os artigos descartados, 41 artigos eram da revista Produção Online. Após uma segunda análise criteriosa do título, resumo, palavras-chave e conteúdo do artigo, que visava selecionar artigos cujo foco de pesquisa era realmente o estudo de APL`s, sobraram 29 artigos que foram analisados em profundidade, conforme se verifica na próxima seção.

\section{Análise dos resultados}

Esta seção tem como finalidade apresentar os resultados da pesquisa sistemática, assim como analisar os resultados encontrados. Os 29 artigos que foram analisados em profundidade podem ser visualizados de forma resumida no Quadro 4 que apresenta as seguintes informações: objetivo do artigo, resultados obtidos, ano de publicação, palavras-chave do artigo, autores, instituição de vínculo dos autores e revista em que foi publicado o artigo. A seguir, são apresentados maiores detalhes sobre a análise desenvolvida.

Quadro 4 - Informações sobre os artigos analisados

\begin{tabular}{|c|c|c|c|c|c|c|}
\hline Objetivo & Resultados & Ano & Palavras-chave & Autores & Instituição & Periódico \\
\hline $\begin{array}{l}\text { Iniciar uma pesquisa in } \\
\text { loco para estudar o } \\
\text { contexto e as inter- } \\
\text { relações entre as } \\
\text { empresas da região } \\
\text { Londrina-Cambé, a partir } \\
\text { do Município de } \\
\text { Londrina, o mais } \\
\text { importante } \\
\text { economicamente da } \\
\text { aglomeração. }\end{array}$ & $\begin{array}{c}\text { A região possui uma } \\
\text { aglomeração informal, } \\
\text { mostrando potencial para um } \\
\text { futuro APL organizado, porém } \\
\text { existe o entrave da cultura, pois } \\
\text { os empresários precisam } \\
\text { aprender a trabalhar em } \\
\text { conjunto. A ação das empresas } \\
\text { inovadoras não se dissemina e } \\
\text { os efeitos sinérgicos da } \\
\text { aglomeração são tênues. }\end{array}$ & 2006 & $\begin{array}{l}\text { APL; Confiança; } \\
\text { Cooperação }\end{array}$ & $\begin{array}{l}\text { Luiz Gustavo } \\
\text { Antonio de } \\
\text { Souza; Márcia } \\
\text { Regina } \\
\text { Gabardo da } \\
\text { Câmara; Marco } \\
\text { Aurélio Arbex }\end{array}$ & UEL/UEM & \\
\hline $\begin{array}{c}\text { Analisar o APL das } \\
\text { Indústrias da Cal da } \\
\text { Região Metropolitana de } \\
\text { Curitiba, identificando } \\
\text { seus aspectos estruturais } \\
\text { e analisando os fatores } \\
\text { competitivos das micro e } \\
\text { pequenas empresas dessa } \\
\text { rede. }\end{array}$ & $\begin{array}{c}\text { Aspectos relativos à } \\
\text { localização da empresa } \\
\text { interferem no seu modo de } \\
\text { gerir. O ambiente externo à } \\
\text { empresa é muito importante } \\
\text { para se definir a } \\
\text { competitividade do local. } \\
\text { Verificou-se que existem } \\
\text { alguns pontos a serem } \\
\text { observados pelas empresas, } \\
\text { para que elas obtenham, } a \\
\text { priori, melhor desempenho em } \\
\text { relação à concorrência. No } \\
\text { modelo de APL há necessidade } \\
\text { de se preparar o empresariado, } \\
\text { para apoiar os processos de } \\
\text { relacionamento entre os atores } \\
\text { participantes do APL. }\end{array}$ & 2009 & $\begin{array}{c}\text { Cal; APL; } \\
\text { Competitividade }\end{array}$ & $\begin{array}{c}\text { Luciana Taís } \\
\text { do Nascimento; } \\
\text { Patrícia } \\
\text { Alcântara } \\
\text { Cardoso; } \\
\text { Edson Pinheiro } \\
\text { de Lima }\end{array}$ & $\begin{array}{c}\text { PUC/PR; } \\
\text { UFES; } \\
\text { UTFPR }\end{array}$ & GEPROS \\
\hline
\end{tabular}




\begin{tabular}{|c|c|c|c|c|c|c|}
\hline $\begin{array}{c}\text { Revisar conceitualmente } \\
\text { as abordagens Arranjos } \\
\text { produtivos locais (APLs) } \\
\text { e cadeias } \\
\text { agroalimentares } \\
\text { concentrando conceitos } \\
\text { em um documento para } \\
\text { servir de base a futuras } \\
\text { pesquisas }\end{array}$ & $\begin{array}{l}\text { Ambos são exemplos de } \\
\text { arranjos, nos quais empresas } \\
\text { individuais e autônomas } \\
\text { unificam e alinham seus } \\
\text { esforços individuais, em busca } \\
\text { de objetivos parciais } \\
\text { individuais e objetivos globais } \\
\text { comuns. O mecanismo de base } \\
\text { que surge nestes arranjos é a } \\
\text { cooperação. }\end{array}$ & 2009 & $\begin{array}{c}\text { Arranjos } \\
\text { produtivos } \\
\text { locais; Cadeias } \\
\text { agro-alimentares; } \\
\text { Cooperação }\end{array}$ & $\begin{array}{c}\text { Luiz Antônio } \\
\text { Machado Vial; } \\
\text { Tânia Cristina } \\
\text { Campanhol } \\
\text { Sette; Vanessa } \\
\text { de Souza } \\
\text { Batisti; Miguel } \\
\text { Afonso Sellitto }\end{array}$ & UNISINOS & \\
\hline $\begin{array}{l}\text { Propor um Sistema de } \\
\text { Medição do Desempenho } \\
\text { (SMD) que dê suporte ao } \\
\text { processo de gestão de } \\
\text { desempenho do APL. }\end{array}$ & $\begin{array}{l}\text { A medição de desempenho } \\
\text { integrada a um processo } \\
\text { sistemático de melhoria } \\
\text { contínua promove a gestão } \\
\text { colaborativa, aprimora o } \\
\text { processo de tomada de decisão } \\
\text { ou coordenação das ações } \\
\text { planejadas pelas instituições, } \\
\text { empresas e outros órgãos que } \\
\text { fazem parte dos APL's. } \\
\end{array}$ & 2009 & $\begin{array}{l}\text { APL; Sistema de } \\
\text { medição de } \\
\text { desempenho; } \\
\text { Melhoria } \\
\text { contínua; } \\
\text { Pequenas e } \\
\text { médias empresas }\end{array}$ & $\begin{array}{c}\text { Edwin } \\
\text { Vladimir } \\
\text { Cardoza } \\
\text { Galdámez; } \\
\text { Luiz Cesar } \\
\text { Ribeiro } \\
\text { Carpinetti; } \\
\text { Mateus Cecílio } \\
\text { Gerolamo }\end{array}$ & $\begin{array}{c}\text { UEM; } \\
\text { USP/EESC }\end{array}$ & \\
\hline $\begin{array}{c}\text { Analisar as } \\
\text { oportunidades para a } \\
\text { integração da dimensão } \\
\text { ambiental em um grupo } \\
\text { de empresas do Polo } \\
\text { Joalheiro de São José do } \\
\text { Rio Preto-SP, } \\
\text { participantes de um } \\
\text { projeto de } \\
\text { competitividade } \\
\text { executado pelo } \\
\text { SEBRAE. }\end{array}$ & $\begin{array}{c}\text { Independente de incentivos ou } \\
\text { exigências dos canais de } \\
\text { distribuição e dos } \\
\text { consumidores que enfatizem a } \\
\text { variável ambiental, as empresas } \\
\text { estão investindo em atualização } \\
\text { tecnológica, para } \\
\text { permanecerem no mercado } \\
\text { competitivo. Por outro lado, } \\
\text { foram identificadas } \\
\text { oportunidades para promover } \\
\text { melhorias no desempenho } \\
\text { ambiental juntamente com a } \\
\text { eficiência produtiva. } \\
\end{array}$ & 2009 & $\begin{array}{l}\text { Produção mais } \\
\text { limpa; Inovação } \\
\text { tecnológica; } \\
\text { Sistemas locais } \\
\text { de produção; } \\
\text { Arranjos } \\
\text { produtivos } \\
\text { locais; Indústria } \\
\text { de joias. }\end{array}$ & $\begin{array}{c}\text { Rosely Mana } \\
\text { Domingues; } \\
\text { Sônia Regina } \\
\text { Paulino }\end{array}$ & $\begin{array}{l}\text { Centro } \\
\text { Universitá- } \\
\text { rio de Rio } \\
\text { Preto - } \\
\text { UNIRP; } \\
\text { Universida- } \\
\text { de de } \\
\text { Araraquara } \\
\text { - UNIARA }\end{array}$ & $\begin{array}{l}\text { Gestão \& } \\
\text { Produção }\end{array}$ \\
\hline $\begin{array}{l}\text { Identificar o estágio de } \\
\text { utilização das Práticas de } \\
\text { Gestão do Conhecimento } \\
\text { (PGC) em uma indústria } \\
\text { do APL do Setor } \\
\text { Moveleiro do município } \\
\text { de Arapongas, Estado do } \\
\text { Paraná. }\end{array}$ & $\begin{array}{c}\text { As PGC apresentadas para a } \\
\text { empresa, em sua maioria } \\
(80 \%) \text {, já estão sendo utilizadas } \\
\text { de alguma forma. O estágio de } \\
\text { implantação do conjunto total } \\
\text { de práticas pesquisadas ainda é } \\
\text { incipiente na indústria } \\
\text { pesquisada, pois, apenas } 25 \% \\
\text { das práticas pesquisadas estão } \\
\text { sendo formalmente utilizadas. }\end{array}$ & 2007 & $\begin{array}{l}\text { Gestão do } \\
\text { conhecimento; } \\
\text { Práticas de } \\
\text { gestão do } \\
\text { conhecimento; } \\
\text { APL }\end{array}$ & $\begin{array}{l}\text { Paula Michelle } \\
\text { Purcidonio; } \\
\text { Antonio Carlos } \\
\text { de Francisco }\end{array}$ & UTFPR & \multirow{3}{*}{$\begin{array}{c}\text { Gestão } \\
\text { Industrial }\end{array}$} \\
\hline $\begin{array}{c}\text { Identificar a } \\
\text { aplicabilidade dos } \\
\text { conceitos e abordagens } \\
\text { de APL, keiretsu de } \\
\text { produção (modelo de } \\
\text { produção japonês) } \\
\text { cluster e sistemas } \\
\text { setoriais de inovação ao } \\
\text { aglomerado de petróleo e } \\
\text { gás do Norte } \\
\text { Fluminense. } \\
\end{array}$ & $\begin{array}{c}\text { O arcabouço teórico proposto } \\
\text { para a análise do aglomerado } \\
\text { de petróleo e gás do Norte } \\
\text { Fluminense é focado na } \\
\text { interseção da abordagem de } \\
\text { cluster e de sistema setorial de } \\
\text { inovação. }\end{array}$ & 2007 & $\begin{array}{l}\text { Inovação; } \\
\text { Aglomerados } \\
\text { industriais; } \\
\text { Indústria de } \\
\text { petróleo e gás. }\end{array}$ & $\begin{array}{c}\text { Bruno dos } \\
\text { Santos } \\
\text { Silvestre; Paulo } \\
\text { Roberto } \\
\text { Tavares Dalcol }\end{array}$ & $\begin{array}{l}\text { ELETRO- } \\
\text { BRÁS; } \\
\text { PUC-Rio }\end{array}$ & \\
\hline $\begin{array}{l}\text { Mostrar, a partir de uma } \\
\text { revisão da literatura e de } \\
\text { estudos empíricos de } \\
\text { APL's no Brasil, uma } \\
\text { análise dos instrumentos } \\
\text { fundamentais para o } \\
\text { desenvolvimento } \\
\text { sustentável dos APL's. }\end{array}$ & $\begin{array}{l}\text { Os instrumentos relacionados } \\
\text { neste trabalho, por } \\
\text { apresentarem fortes relações e } \\
\text { implicações entre si, devem ser } \\
\text { tratados como se constituíssem } \\
\text { um sistema, caso contrário, o } \\
\text { estudo isolado sem a } \\
\text { consideração dos outros temas, } \\
\text { torna precária a análise do } \\
\text { sistema como um todo e sua } \\
\text { orientação para um } \\
\text { desenvolvimento pleno. }\end{array}$ & 2007 & $\begin{array}{l}\text { Arranjos } \\
\text { Produtivos } \\
\text { Locais; Política } \\
\text { Industrial e } \\
\text { Tecnológica; } \\
\text { Governança; } \\
\text { Cooperação; } \\
\text { Inovação }\end{array}$ & $\begin{array}{c}\text { Antonio } \\
\text { Iacono; } \\
\text { Marcelo Seido } \\
\text { Nagano }\end{array}$ & EESC-USP & \\
\hline
\end{tabular}




\begin{tabular}{|c|c|c|c|c|c|c|}
\hline $\begin{array}{c}\text { Examinar o grau de } \\
\text { desenvolvimento } \\
\text { municipal ao longo de } \\
\text { três décadas sucessivas, } \\
\text { anos } 70,80 \text { e } 90 \text { e } \\
\text { apontar a formação de } 4 \\
\text { grandes pólos logísticos, } \\
\text { a partir de aglomerados } \\
\text { de empresas e } \\
\text { instituições locais } \\
\text { colaborativas de } \\
\text { trabalho. }\end{array}$ & $\begin{array}{l}\text { O mapeamento dos quatro } \\
\text { polos logísticos deve ser feito } \\
\text { regularmente, e servir como } \\
\text { indicador de posições } \\
\text { estratégicas, e apontar áreas } \\
\text { logísticas sustentáveis, bem } \\
\text { como a evolução do setor de } \\
\text { serviços locais. }\end{array}$ & 2008 & $\begin{array}{l}\text { Meio ambiente; } \\
\text { Pólos regionais; } \\
\text { Sustentabilidade }\end{array}$ & $\begin{array}{c}\text { Marly } \\
\text { Cavalcanti; } \\
\text { Osvaldo Elias } \\
\text { Farah }\end{array}$ & $\begin{array}{c}\text { Universida- } \\
\text { de - Centro } \\
\text { Paula } \\
\text { Souza; } \\
\text { UNIMEP }\end{array}$ & \\
\hline $\begin{array}{c}\text { Analisar o nível de } \\
\text { competitividade do APL } \\
\text { de desenvolvimento de } \\
\text { Software da cidade de } \\
\text { João Pessoa. }\end{array}$ & $\begin{array}{c}\text { Permite inferir que o APL de } \\
\text { desenvolvimento de software } \\
\text { de João Pessoa apresenta nível } \\
\text { de competitividade positivo. } \\
\text { No entanto, ficou perceptível } \\
\text { que há necessidade de } \\
\text { intensificação da cooperação } \\
\text { político-institucional, com } \\
\text { políticas e ações que } \\
\text { contribuam na geração e no } \\
\text { fortalecimento do } \\
\text { desenvolvimento produtivo e } \\
\text { da competitividade. }\end{array}$ & 2009 & $\begin{array}{c}\text { Desenvolvimento } \\
\text { social; Software; } \\
\text { Competitividade; } \\
\text { APL's }\end{array}$ & $\begin{array}{l}\text { Jailma Araújo } \\
\text { dos Santos; } \\
\text { Ivani Costa; } \\
\text { Bartira Pereira } \\
\text { Amorim; } \\
\text { Gesinaldo } \\
\text { Ataíde Cândido }\end{array}$ & $\begin{array}{l}\text { SEBRAE; } \\
\text { IFPB; } \\
\text { UFCG }\end{array}$ & \\
\hline $\begin{array}{l}\text { Analisar, baseado no } \\
\text { modelo do DGC, como } \\
\text { se estrutura a utilização } \\
\text { do conhecimento nas } \\
\text { organizações, } \\
\text { identificando também } \\
\text { práticas associadas à } \\
\text { geração de } \\
\text { conhecimentos nas } \\
\text { empresas através da } \\
\text { experiência dos gestores. }\end{array}$ & $\begin{array}{l}\text { As empresas não têm uma } \\
\text { estrutura ideal para } \\
\text { aproveitamento do } \\
\text { conhecimento em suas } \\
\text { atividades e os poucos casos de } \\
\text { práticas associadas ao } \\
\text { aproveitamento do } \\
\text { conhecimento focam suas } \\
\text { ações de gestão em níveis } \\
\text { táticos dirimindo atuações de } \\
\text { nível estratégico, o que pode } \\
\text { prejudicar a competitividade da } \\
\text { organização. }\end{array}$ & 2009 & $\begin{array}{l}\text { Gestão do } \\
\text { Conhecimento; } \\
\text { Processo; } \\
\text { Diagnóstico }\end{array}$ & $\begin{array}{l}\text { Ricardo Jorge } \\
\text { Araújo Silva; } \\
\text { Abraham } \\
\text { Benzaquen } \\
\text { Sicsú; Antônio } \\
\text { Pires } \\
\text { Crisóstomo }\end{array}$ & UFPE & \\
\hline $\begin{array}{l}\text { Explorar as relações } \\
\text { existentes entre os } \\
\text { conceitos de governança, } \\
\text { competitividade e } \\
\text { sustentabilidade no } \\
\text { âmbito dos Arranjos } \\
\text { Produtivos Locais. }\end{array}$ & $\begin{array}{c}\text { A governança, como a } \\
\text { capacidade de articulação dos } \\
\text { atores em torno de objetivos } \\
\text { comuns, tem a capacidade de } \\
\text { interferir não só na } \\
\text { competitividade dos arranjos } \\
\text { como na promoção de um } \\
\text { desenvolvimento sustentável. }\end{array}$ & 2009 & $\begin{array}{c}\text { Sustentabilidade; } \\
\text { Competitividade; } \\
\text { Governança }\end{array}$ & $\begin{array}{c}\text { Sandra Maria } \\
\text { Araújo de } \\
\text { Souza; } \\
\text { Gesinaldo } \\
\text { Ataíde Cândido }\end{array}$ & UFCG & \\
\hline $\begin{array}{c}\text { Descrever a aplicação de } \\
\text { práticas de } \\
\text { sustentabilidade } \\
\text { empresarial do APL } \\
\text { Calçadista de Campina } \\
\text { Grande - PB. }\end{array}$ & $\begin{array}{l}\text { Recomenda-se que o APL } \\
\text { Calçadista de Campina Grande } \\
\text { busque formas alternativas de } \\
\text { fomentar sua sustentabilidade } \\
\text { empresarial, através de práticas } \\
\text { efetivas que integrem aspectos } \\
\text { sociais, ambientais e } \\
\text { econômicos para que } \\
\text { promovam o desenvolvimento. }\end{array}$ & 2010 & $\begin{array}{c}\text { APL; } \\
\text { Sustentabilidade } \\
\text { social; } \\
\text { Sustentabilidade } \\
\text { econômica; } \\
\text { Sustentabilidade } \\
\text { ambiental }\end{array}$ & $\begin{array}{c}\text { Raquel } \\
\text { Andrade } \\
\text { Barros; } \\
\text { Elisabeth de } \\
\text { Oliveira } \\
\text { Andrade; Ana } \\
\text { Cecília Feitosa } \\
\text { de } \\
\text { Vasconcelos; } \\
\text { Gesinaldo } \\
\text { Ataíde Cândido }\end{array}$ & $\begin{array}{l}\text { UFPB; } \\
\text { UFCG }\end{array}$ & \\
\hline $\begin{array}{l}\text { Propor uma abordagem } \\
\text { para o estudo da } \\
\text { dinâmica competitiva de } \\
\text { empresas em APL's. }\end{array}$ & $\begin{array}{c}\text { A abordagem proposta } \\
\text { mostrou-se robusta para o } \\
\text { entendimento da dinâmica } \\
\text { competitiva no pólo estudado, } \\
\text { captando a diversidade } \\
\text { existente e os padrões } \\
\text { característicos de cada grupo, } \\
\text { com perspectivas promissoras } \\
\text { de aplicação a outros APL's. }\end{array}$ & $2006 a$ & $\begin{array}{l}\text { Mudança } \\
\text { tecnológica; } \\
\text { APL; Cerâmica } \\
\text { vermelha. }\end{array}$ & $\begin{array}{c}\text { Sebastião } \\
\text { Décio Coimbra } \\
\text { de Souza; José } \\
\text { Arica }\end{array}$ & UENF & Produção \\
\hline
\end{tabular}




\begin{tabular}{|c|c|c|c|c|c|c|}
\hline $\begin{array}{c}\text { Apresentar uma } \\
\text { avaliação comparativa } \\
\text { entre as abordagens de } \\
\text { Sistemas de Inovação e o } \\
\text { Diamante de Porter para } \\
\text { analisar a } \\
\text { competitividade de } \\
\text { aglomerados e sistemas } \\
\text { produtivos locais. }\end{array}$ & $\begin{array}{l}\text { A conjugação dos preceitos } \\
\text { assumidos no modelo } \\
\text { Diamante e na estrutura de } \\
\text { Sistemas de Inovação, através } \\
\text { de uma perspectiva } \\
\text { evolucionária, pode prover } \\
\text { contribuições importantes para } \\
\text { entendimento da mudança } \\
\text { tecnológica e da dinâmica } \\
\text { competitiva de certos APL's, } \\
\text { preenchendo lacunas referentes } \\
\text { à sustentação teórica. }\end{array}$ & $2006 b$ & $\begin{array}{c}\text { Arranjos } \\
\text { produtivos } \\
\text { locais; Sistemas } \\
\text { de inovação; } \\
\text { Diamante de } \\
\text { Porter; } \\
\text { Abordagem } \\
\text { evolucionária }\end{array}$ & $\begin{array}{c}\text { Sebastião } \\
\text { Décio Coimbra } \\
\text { de Souza; José } \\
\text { Arica }\end{array}$ & UENF & \\
\hline $\begin{array}{l}\text { Contribuir para o estudo } \\
\text { das redes de } \\
\text { conhecimento em } \\
\text { aglomerações produtivas } \\
\text { por meio da análise de } \\
\text { processos de aprendizado } \\
\text { de pequenas e médias } \\
\text { empresas (PMEs) de } \\
\text { software. } \\
\end{array}$ & $\begin{array}{l}\text { Corroboram com a proposição } \\
\text { de que os processos de } \\
\text { aprendizagem por interação são } \\
\text { determinantes para as PMEs de } \\
\text { software na construção de } \\
\text { conhecimentos e geração de } \\
\text { capacitações inovativas. }\end{array}$ & 2012 & $\begin{array}{l}\text { Aprendizagem; } \\
\text { Conhecimento; } \\
\text { PMEs; Arranjos } \\
\text { produtivos } \\
\text { locais; Redes de } \\
\text { cooperação } \\
\text { produtiva }\end{array}$ & $\begin{array}{l}\text { Ana Paula dos } \\
\text { Reis; João } \\
\text { Amato Neto }\end{array}$ & EPUSP & \\
\hline $\begin{array}{l}\text { Identificar no setor metal } \\
\text { mecânico um APL no } \\
\text { Sudoeste do Paraná e } \\
\text { como seria implantado. }\end{array}$ & $\begin{array}{l}\text { O arranjo foi identificado e é } \\
\text { possível sua implantação, mas } \\
\text { é necessária a colaboração } \\
\text { empresarial e participação dos } \\
\text { organismos de classe, } \\
\text { governamentais, de fomento e } \\
\text { assessoria. }\end{array}$ & 2005 & $\begin{array}{l}\text { APL's; Clusters; } \\
\text { Desenvolvimento } \\
\text { regional }\end{array}$ & $\begin{array}{l}\text { João Carlos } \\
\text { Chiochetta; } \\
\text { Kazuo } \\
\text { Hatakeyama }\end{array}$ & UTFPR & \multirow{4}{*}{$\begin{array}{c}\text { Produção } \\
\text { Online }\end{array}$} \\
\hline $\begin{array}{l}\text { Analisar a redução de } \\
\text { custos no uso de APL's } \\
\text { como estratégia de } \\
\text { gestão competitiva na } \\
\text { logística de suprimentos } \\
\text { das empresas, utilizando- } \\
\text { se do caso de um APL de } \\
\text { cadeia produtiva do leite } \\
\text { no Estado do Ceará, } \\
\text { denominado, neste } \\
\text { estudo, como APL Leite } \\
\text { \& Sol. }\end{array}$ & $\begin{array}{l}\text { O APL analisado apresentou-se } \\
\text { técnica e economicamente } \\
\text { viável, apresentando um } \\
\text { resultado positivo no período } \\
\text { analisado. O APL tornou } \\
\text { possível a venda de um novo } \\
\text { produto pelos produtores de } \\
\text { leite, como também a } \\
\text { existência de economia no } \\
\text { custo de aquisição da torta de } \\
\text { algodão, que permitiu a } \\
\text { realização de um estoque para } \\
\text { o período seguinte e ainda } \\
\text { gerou uma receita com a venda } \\
\text { para outros produtores. }\end{array}$ & 2007 & $\begin{array}{c}\text { Arranjos } \\
\text { Produtivos; } \\
\text { Custos; Logística } \\
\text { de Suprimentos }\end{array}$ & $\begin{array}{l}\text { Célia Maria } \\
\text { Braga } \\
\text { Carneiro; } \\
\text { Edmar José } \\
\text { Zorzal; } \\
\text { Greyciane } \\
\text { Passos dos } \\
\text { Santos; Marta } \\
\text { Maria de } \\
\text { Mendonça } \\
\text { Bastos; Rosana } \\
\text { Venâncio } \\
\text { Nunes; } \\
\text { Rosângela } \\
\text { Venâncio } \\
\text { Nunes }\end{array}$ & $\begin{array}{l}\text { UFC; } \\
\text { Faculdade } \\
\text { Novo } \\
\text { Milênio }\end{array}$ & \\
\hline $\begin{array}{l}\text { Sugerir a aplicação do } \\
\text { método PDCA para } \\
\text { organizar as ações de } \\
\text { implantação de um } \\
\text { Sistema Produtivo Local } \\
\text { no setor de Móveis de } \\
\text { Metal e Sistemas de } \\
\text { Armazenagem e } \\
\text { Logística na região dos } \\
\text { Campos Gerais, Paraná. }\end{array}$ & $\begin{array}{l}\text { O arranjo estudado neste artigo } \\
\text { apresenta estatisticamente um } \\
\text { grande potencial para a } \\
\text { estruturação de um APL. } \\
\text { Portanto, em conjunto com esta } \\
\text { vontade comum, e com o } \\
\text { auxílio do método PDCA, } \\
\text { melhorias podem ser } \\
\text { alcançadas pelo grupo. Ações } \\
\text { conjuntas permitem que as } \\
\text { pequenas empresas alcancem } \\
\text { economias de escala, inovação, } \\
\text { e outras vantagens. }\end{array}$ & 2009 & $\begin{array}{l}\text { Sistemas } \\
\text { produtivos } \\
\text { locais; PDCA; } \\
\text { Móveis de metal; } \\
\text { Sistemas de } \\
\text { armazenagem e } \\
\text { logística }\end{array}$ & $\begin{array}{l}\text { Regina Negri } \\
\text { Pagani; Luis } \\
\text { Mauricio de } \\
\text { Resende; Rui } \\
\text { Francisco } \\
\text { Martins Marçal }\end{array}$ & $\begin{array}{l}\text { Faculdade } \\
\text { Educaciona } \\
1 \text { de Ponta } \\
\text { Grossa - } \\
\text { Faculdade } \\
\text { União; } \\
\text { UTFPR }\end{array}$ & \\
\hline $\begin{array}{l}\text { Mostrar a aplicação de } \\
\text { um modelo de } \\
\text { elaboração de estratégia } \\
\text { de produção que pode } \\
\text { auxiliar o desempenho } \\
\text { competitivo de empresas } \\
\text { situadas em APL's. }\end{array}$ & $\begin{array}{l}\text { Os resultados da aplicação } \\
\text { revelam problemas que são } \\
\text { comuns a estes tipos de } \\
\text { ambientes, entre os quais se } \\
\text { destacam a falta de } \\
\text { conhecimento sobre } \\
\text { as demandas de mercado e a } \\
\text { ausência de instrumentos } \\
\text { gerenciais capazes de avaliar e } \\
\text { propor melhorias que levem ao } \\
\text { aumento do desempenho da } \\
\text { produção. }\end{array}$ & 2010 & $\begin{array}{l}\text { Estratégia de } \\
\text { Produção; } \\
\text { Modelo Platts e } \\
\text { Gregory; } \\
\text { Cerâmica } \\
\text { Branca; APL }\end{array}$ & $\begin{array}{c}\text { Daniela } \\
\text { Tatiane dos } \\
\text { Santos; Mário } \\
\text { Otávio Batalha }\end{array}$ & UFSCar & \\
\hline
\end{tabular}


Avaliar o nível de maturidade do APL de bonés de Apucarana PR, de modo que seja possível identificar os aspectos que envolvem a cadeia produtiva que necessitam de melhorias.

\begin{tabular}{|l|}
\hline \\
\hline
\end{tabular}

Apresentar a aplicação de uma estrutura para o caso do APL moveleiro de Ubá, o que pode contribuir para identificação de pontos que merecem mais cuidado por parte das empresas e que se mostram importantes para sua sobrevivência e desenvolvimento.

\begin{tabular}{|c|} 
\\
\hline Explorar no âmbito da \\
ABEPRO os artigos \\
relacionados às
\end{tabular}
aglomerações produtivas, no período de 2005 a 2009, detalhando as análises nos anos de 2008 e 2009.

Estudar,
preliminarmente, as
definições e as
diferenças dos principais Arranjos Empresariais, devido à escassez de definições uniformizadas na literatura, que tornem possível diferenciar cada tipo de Arranjo, principalmente aqueles em que as definições mais se assemelham.

Aplicar no pólo de moda íntima de Nova Friburgo, RJ uma metodologia de gestão do conhecimento para APL, construído a partir de algumas referências teóricas e da experiência prática do Centro de Referência em Inteligência Empresarial.
Obtiveram-se informações que melhorias por parte da obtido foi positivo, porém aponta melhorias que podem da governança para o aumento da competitividade das empresas e consequente aquecimento da economia local/regional.

A partir das visitas às empresas moveleiras de Ubá, a premissa da estratificação em grupos com diferentes padrões competitivos foi confirmada. terão utilidade na realização de governança do APL. O escore ser realizadas na rede por parte

\begin{tabular}{|l|l|l} 
& \\
\hline & & \\
& & \\
& & \\
& &
\end{tabular}

APL
Desenvolvin

Petter; L

Petter; Luis

Maurício

Resende;

produtivos

Competitividade

Fabrício

Alexandre

Alves Ceranto

And

Andréia

Aparecida

Albino;

Sebastião

APL; APL

Moveleiro de

Décio Coimbra

de Souza;

Ubá; Abordagem

Afonso

Augusto

2011 Evolucionária;

Estratificação de

Padrões

Competitivos;

Cadeia de Valor

Teixeira de

Freitas de

Carvalho Lima;

Marcos Inácio

Severo de

Almeida;

Ricardo

Roberto Behr

$28 \%$ dos artigos são sobre APL

e $61 \%$ sobre Clusters; $81 \%$ das

publicações foram de 2005 até

2007; Ocorreram muitas

publicações em 2007 por ter

sido criada uma subárea

relacionada a redes e aglomerações.

Após analisar as definições de diversos autores constatou-se que APL e Cluster são os que mais apresentam semelhanças. Da forma como estes Arranjos vêm sendo conceituados levase a um falso entendimento de que os dois seriam um tipo único, situação esta que

dificultou a formação de uma diferença mais forte entre os mesmos.

Mostrou que o estágio de evolução do APL é de baixa governança no que tange a sua integração estratégica. Existe uma governança, realizada pelo Conselho de Moda, que faz com que exista alguma interação estratégica entre as empresas de confecções do pólo, ainda que muitas delas hajam exclusivamente por conta própria.

UTFPR

Faculdade

Presidente

Antônio

Carlos de

Ponte

Nova;

UENF;

UFV;

UFG;

UFES

Jaqueline de

Fátima

Cardoso;

2011

produtivo(s)

Local(is);

Rede(s) de

Empresas;

Cluster(s); ABEPRO

Janaína Gularte

Cardoso;

Nelson

Casarotto Filho

$\mathrm{IF} / \mathrm{SC}$

UFSC

\begin{tabular}{l|l} 
Casarotto Filho & \\
\end{tabular}

2012

Arranjos

Empresariais;

Definições;

Diferenças

Anderson

Tiago Peixoto

Gonçalves;

Maria Silene

Alexandre

Leite; Ricardo

Moreira da

Silva
Gestão do conhecimento;

Inteligência empresarial; APL's
Marcos

Cavalcanti;

Rosa Lima;

André Pereira

Neto
UFRJ;

UERJ
Produto \& Produção 


\begin{tabular}{|c|c|c|c|c|c|c|}
\hline $\begin{array}{l}\text { Propor um modelo para } \\
\text { avaliação sistêmica do } \\
\text { desempenho competitivo } \\
\text { de arranjos produtivos. } \\
\text { Analisar a aplicabilidade } \\
\text { do instrumento com um } \\
\text { estudo de caso no setor } \\
\text { coureiro-calçadista do } \\
\text { Vale dos Sinos. } \\
\end{array}$ & $\begin{array}{l}\text { Resultados da aplicação do } \\
\text { modelo apresentam um mapa } \\
\text { com forças e fraquezas do } \\
\text { setor. As conclusões do } \\
\text { trabalham indicam que a versão } \\
\text { final do modelo pode também } \\
\text { ser usado para análise de } \\
\text { desempenho em diferentes } \\
\text { arranjos produtivos. }\end{array}$ & 2009 & $\begin{array}{c}\text { Arranjos } \\
\text { produtivos; } \\
\text { Competitividade } \\
\text { sistêmica; } \\
\text { Medição de } \\
\text { desempenho }\end{array}$ & $\begin{array}{l}\text { Peter Bent } \\
\text { Hansen; } \\
\text { Leonardo } \\
\text { Rocha de } \\
\text { Oliveira }\end{array}$ & PUCRS & \\
\hline $\begin{array}{c}\text { Identificar as ações de } \\
\text { cooperação existentes } \\
\text { entre empresas } \\
\text { pertencentes à APL's, } \\
\text { tendo como universo de } \\
\text { pesquisa os } 23 \text { arranjos } \\
\text { do Paraná, classificados } \\
\text { na tipologia de APL's } \\
\text { pela Secretaria do } \\
\text { Planejamento do Paraná } \\
\text { e pela FIEP. } \\
\end{array}$ & $\begin{array}{l}\text { Foram identificadas } 25 \text { ações } \\
\text { cooperativas, das quais são } \\
\text { caracterizadas por este trabalho } \\
\text { como ações de cooperação } \\
\text { interfirmas, ocorrentes } \\
\text { especificamente na tipologia de } \\
\text { APL's. }\end{array}$ & $2011 a$ & $\begin{array}{l}\text { Cooperação; } \\
\text { APL's }\end{array}$ & $\begin{array}{c}\text { Rodolfo } \\
\text { Reinaldo } \\
\text { Petter; Fabrício } \\
\text { Alexandre } \\
\text { Alves Ceranto; } \\
\text { Luis Mauricio } \\
\text { Martins de } \\
\text { Resende }\end{array}$ & UTFPR & \\
\hline $\begin{array}{c}\text { Identificar o } \\
\text { comportamento } \\
\text { predominante adotado } \\
\text { pelo APL de confecções } \\
\text { do Agreste } \\
\text { Pernambucano, através } \\
\text { da aplicação da Matriz } \\
\text { ConFlex }\end{array}$ & $\begin{array}{l}\text { O APL do setor de Confecções } \\
\text { do Agreste Pernambucano } \\
\text { apresenta alta competitividade, } \\
\text { identificado a partir do baixo } \\
\text { nível de confiança, o que } \\
\text { evidencia possível resistência à } \\
\text { construção de relacionamentos } \\
\text { duradouros no arranjo, assim } \\
\text { como ao baixo nível de } \\
\text { flexibilidade. }\end{array}$ & 2010 & $\begin{array}{l}\text { Redes; Arranjos } \\
\text { Produtivos } \\
\text { Locais; } \\
\text { Comportamento } \\
\text { organizacional }\end{array}$ & $\begin{array}{c}\text { Elisabeth de } \\
\text { Oliveira } \\
\text { Andrade; } \\
\text { Maria de } \\
\text { Fátima } \\
\text { Martins; Ana } \\
\text { Cecília Feitosa } \\
\text { de } \\
\text { Vasconcelos; } \\
\text { Patrícia } \\
\text { Trindade } \\
\text { Caldas; } \\
\text { Gesinaldo } \\
\text { Ataíde Cândido }\end{array}$ & $\begin{array}{l}\text { UFCG; } \\
\text { UFPB }\end{array}$ & \multirow[t]{2}{*}{$\begin{array}{l}\text { Sistemas } \\
\text { \& Gestão }\end{array}$} \\
\hline $\begin{array}{l}\text { Conseguir, a partir da } \\
\text { observação de uma } \\
\text { amostra das empresas do } \\
\text { Paraná, analisar se esses } \\
\text { instrumentos de apoio à } \\
\text { inovação tecnológica } \\
\text { estão sendo conhecidos e } \\
\text { utilizados por estas } \\
\text { empresas. }\end{array}$ & $\begin{array}{l}\text { Necessidade de viabilizar estes } \\
\text { instrumentos eficientemente, } \\
\text { fazendo com que eles cheguem } \\
\text { até as empresas e supram as } \\
\text { demandas necessárias para se } \\
\text { inovar. Portanto, a pesquisa } \\
\text { atendeu seu objetivo ao obter } \\
\text { indícios a respeito da utilização } \\
\text { dos instrumentos e, portanto, } \\
\text { com relação à eficácia destes. }\end{array}$ & 2011 & $\begin{array}{c}\text { Inovação } \\
\text { Tecnológica; } \\
\text { APL; } \\
\text { Instrumentos de } \\
\text { Apoio à } \\
\text { Inovação } \\
\text { Tecnológica }\end{array}$ & $\begin{array}{c}\text { Ariane Marcela } \\
\text { Côrtes; Cezar } \\
\text { Augusto } \\
\text { Romano; Paulo } \\
\text { Alberto Barros } \\
\text { Jr. }\end{array}$ & $\begin{array}{l}\text { UTFPR; } \\
\text { Faculdade } \\
\text { de } \\
\text { Educação } \\
\text { Superior do } \\
\text { Paraná } \\
\text { (FESP) }\end{array}$ & \\
\hline
\end{tabular}

Fonte: Elaborado pelos autores

\subsection{Evolução das publicações}

Conforme pode ser observado no Gráfico 1 nos períodos de 2002 a 2004 não foi encontrada nenhuma publicação sobre APL's nos periódicos de Engenharia de Produção (EP) pesquisados. O Gráfico 1 também demonstra que as pesquisas estavam em uma tendência de crescimento até o ano de 2009 e em seguida começaram a cair, variando de nove artigos no ano de 2009 para apenas dois no ano de 2012.

Uma informação que pode auxiliar é a média de artigos publicados por ano que é igual a 2,6 artigos/ano, que representa uma quantidade baixa de pesquisas em APL nos periódicos pesquisados. Conforme destacado anteriormente, o tema APL é considerado um assunto recente para a área de $\mathrm{EP}$, demandando a necessidade do desenvolvimento de mais pesquisas sobre a temática. 
Gráfico 1 - Evolução das pesquisas sobre APL nos periódicos de EP

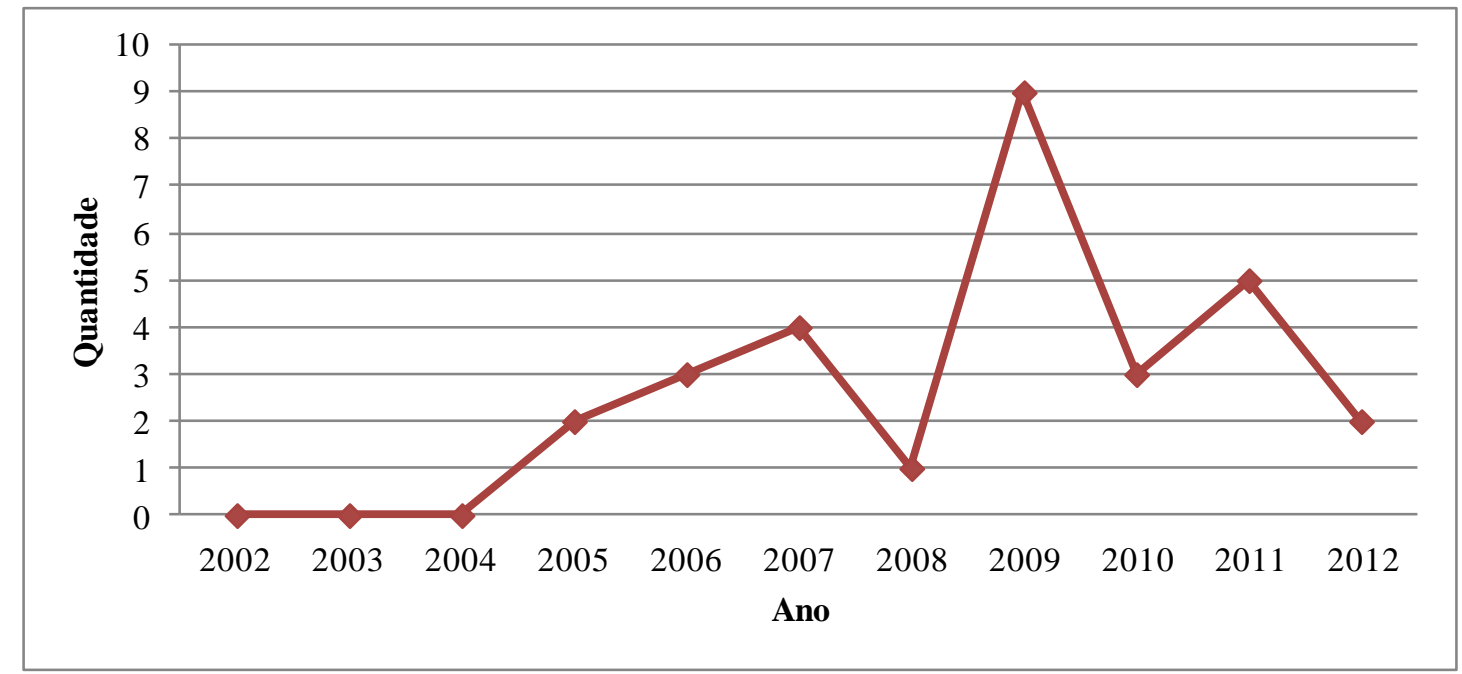

Fonte: Elaborado pelos autores

\subsection{Contribuição por periódico}

Os periódicos Produção Online e Gestão Industrial foram os que mais se destacaram em relação à quantidade de artigos publicados sobre a temática, sendo oito o total de artigos publicados em cada revista, representando mais da metade de todos os artigos publicados sobre APL nos periódicos analisados. Os outros cinco periódicos que publicaram sobre o tema objeto de investigação dentro do período que compreendeu a pesquisa podem ser visualizados no Gráfico 2 . Esses periódicos tiveram uma produção menor ou igual a três artigos por periódico no período de 2002 a 2012.

Gráfico 2 - Artigos publicados por periódico

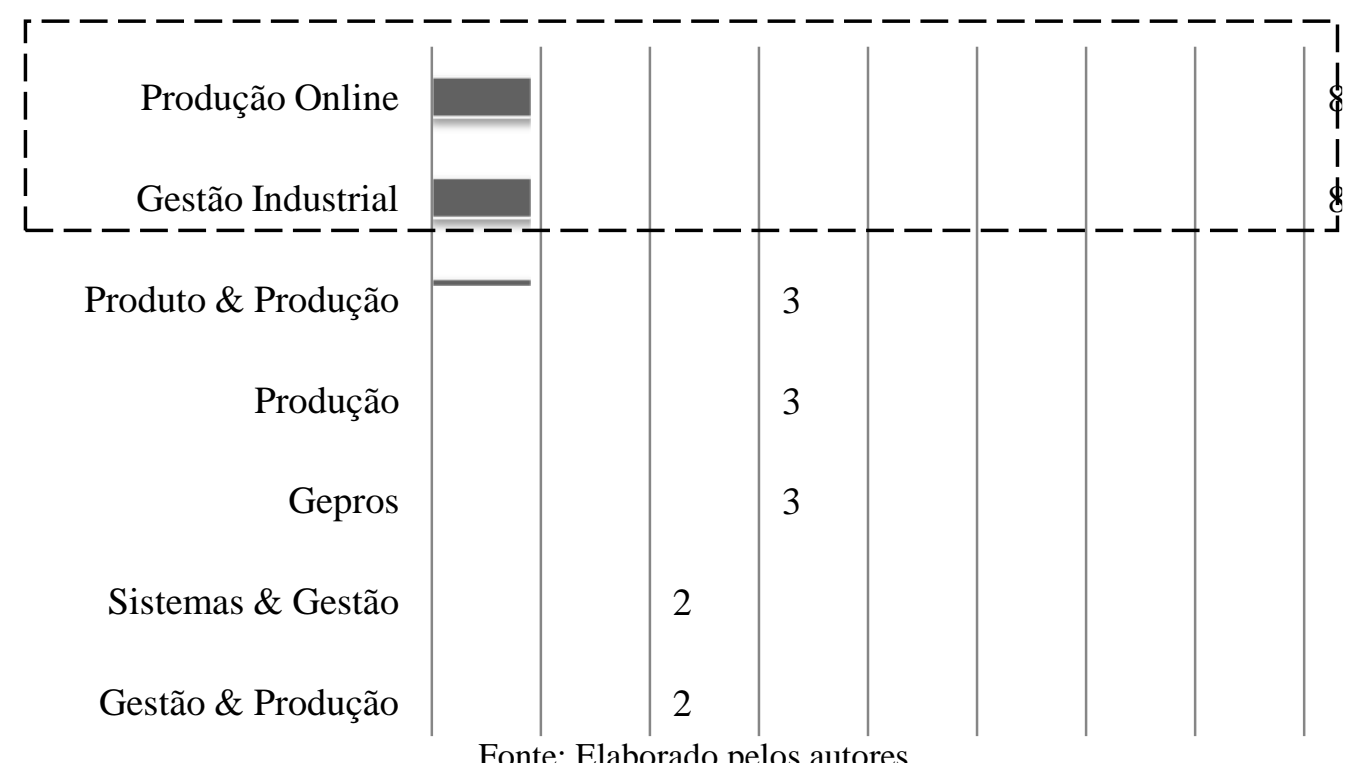

Fonte: Elaborado pelos autores

\subsection{Tipos de APL's pesquisados}

Os tipos de Arranjos Produtivos que foram pesquisados nos diferentes artigos podem ser visualizados no Quadro 5. De acordo com a pesquisa realizada, pôde-se constatar que foram vários 
os tipos de APL's estudados, totalizando 40 (embora o número de artigos analisados na pesquisa seja de 29, foi identificado um número maior de APL's pesquisados, devido ao fato de que em alguns artigos eram estudados mais de um tipo de APL).

De acordo com o Quadro 5 verifica-se que em grande parte das pesquisas apresentadas nos artigos foram desenvolvidos estudos empíricos, demonstrando que os estudos sobre APL dentro da área de Engenharia de Produção, em sua grande maioria, tem a preocupação de se aplicar conceitos e teorias dentro das empresas que fazem parte do APL, conforme também pode ser observado na pesquisa de Nakano (2010) que, em uma análise feita nos Anais do ENEGEP, verificou que grande parte das publicações em Engenharia de Produção são empíricas, indicando que as pesquisas nacionais têm amadurecido e se fortalecido ao longo dos anos.

Quadro 5 - Tipo de APL pesquisado

\begin{tabular}{|c|c|}
\hline Tipo de APL & Quantidade de artigos \\
\hline Calçadista & 5 \\
\hline Software & 5 \\
\hline Moveleiro & 3 \\
\hline Bonés & 2 \\
\hline Ceramista & 2 \\
\hline Móveis de metal e sistemas de armazenagem e logística & 2 \\
\hline Vestuário & 2 \\
\hline Confecções & 1 \\
\hline Indústria de Bordados de Cama, Mesa e Banho & 1 \\
\hline Indústria de Cal e Calcário & 1 \\
\hline Instrumentos médico-odontológicos & 1 \\
\hline Joalheiro & 1 \\
\hline Leite & 1 \\
\hline Madeira e esquadrias & 1 \\
\hline Mandioca e fécula & 1 \\
\hline Metal mecânico & 1 \\
\hline Petróleo e Gás & 1 \\
\hline Polo de moda íntima & 1 \\
\hline Utensílios domésticos e produtos em alumínio & 1 \\
\hline Artigos teóricos que não abordavam nenhum tipo específico de APL & 7 \\
\hline TOTAL DE APL'S PESQUISADOS & 40 \\
\hline
\end{tabular}

Fonte: Elaborado pelos autores

De acordo com o Quadro 5 verifica-se que em grande parte das pesquisas apresentadas nos artigos foram desenvolvidos estudos empíricos, demonstrando que os estudos sobre APL dentro da área de Engenharia de Produção, em sua grande maioria, tem a preocupação de se aplicar conceitos 
e teorias dentro das empresas que fazem parte do APL, conforme também pode ser observado na pesquisa de Nakano (2010) que, em uma análise feita nos Anais do ENEGEP, verificou que grande parte das publicações em Engenharia de Produção são empíricas, indicando que as pesquisas nacionais têm amadurecido e se fortalecido ao longo dos anos.

Além disso, tal fato representa o preceito básico da Engenharia de Produção que consiste em estudar aspectos relacionados ao "projeto, aperfeiçoamento e implantação de sistemas integrados de pessoas, materiais, informações, equipamentos e energia, para a produção de bens e serviços" (FLEURY, 2008, p. 1).

\subsection{Definições de APL apresentadas}

O Quadro 6 apresenta os principais autores que foram citados nos artigos analisados em relação à definição de Arranjos Produtivos Locais. Na última coluna do mesmo Quadro também pode ser verificado quem foram os autores mais citados. Conforme se pode verificar no Quadro 6, são representados apenas os autores que foram mais citados nos artigos analisados, dessa forma, foram desconsiderados os autores que foram citados em menos de quatro artigos.

Quadro 6 - Autores mais citados nos artigos em relação à definição de APL's

\begin{tabular}{|c|c|c|c|c|c|c|c|c|}
\hline \multirow[b]{2}{*}{ AUTORES } & \multicolumn{8}{|c|}{ QUANTIDADE DE ARTIGOS } \\
\hline & GEPROS & $\begin{array}{l}\text { Gestão \& } \\
\text { Produção }\end{array}$ & $\begin{array}{c}\text { Gestão } \\
\text { Industrial }\end{array}$ & Produção & $\begin{array}{l}\text { Produção } \\
\text { Online }\end{array}$ & $\begin{array}{l}\text { Produto \& } \\
\text { Produção }\end{array}$ & $\begin{array}{l}\text { Sistemas \& } \\
\text { Gestão }\end{array}$ & $\begin{array}{c}\text { Total de } \\
\text { artigos }\end{array}$ \\
\hline $\begin{array}{l}\text { CASSIOLATO, } \\
\text { J. E. }\end{array}$ & 1 & 1 & 5 & 2 & 6 & 2 & 1 & 18 \\
\hline $\begin{array}{c}\text { LASTRES, H. } \\
\text { M. M. }\end{array}$ & 2 & 2 & 2 & 2 & 4 & 2 & 1 & 15 \\
\hline REDESIST & 1 & & 1 & 1 & 3 & 1 & & 7 \\
\hline SZAPIRO, M. & 1 & & 3 & & 2 & & & 6 \\
\hline $\begin{array}{l}\text { CASAROTTO } \\
\text { FILHO, N. }\end{array}$ & 1 & 1 & 1 & & 2 & & 1 & 6 \\
\hline $\begin{array}{l}\text { AMATO } \\
\text { NETO, J. }\end{array}$ & 1 & & 1 & & 3 & & & 5 \\
\hline BRITTO, J. & & & 1 & & 3 & 1 & & 5 \\
\hline PIRES, L. H. & 1 & & 1 & & 2 & & 1 & 5 \\
\hline ALBAGLI, S. & & & 1 & & 2 & 1 & & 4 \\
\hline BNDES & & & 1 & 1 & 2 & & & 4 \\
\hline SUZIGAN, W & & & 1 & 1 & 2 & & & 4 \\
\hline
\end{tabular}

Fonte: Elaborado pelos autores

Cassiolato e Lastres foram citados 33 vezes e em todos os artigos analisados (29 artigos), sendo citados, portanto, mais de uma vez em um mesmo artigo. Isso demostra a relevância desses autores no que tange ao desenvolvimento da temática APL ao longo dos anos. Esses autores são os 
coordenadores do glossário da RedeSist, que é uma rede de pesquisa sobre os APL's organizada pela UFRJ, sendo esta rede a terceira mais citada.

\subsection{Métodos de pesquisa adotados}

Os principais métodos de pesquisa adotados nos artigos analisados foram o estudo de caso (22 artigos), a pesquisa bibliográfica (6 artigos) e a pesquisa-ação (1 artigo), demonstrando que grande parte das pesquisas sobre APL's na Engenharia de Produção são qualitativas, conforme pode ser observado nos Gráficos 3 e 4 ilustrados a seguir.

Este resultado reflete as mesmas conclusões de Nakano (2010) acerca da pesquisa desenvolvida nos Anais de ENEGEP. De acordo com o autor, em uma análise feita nos Anais entre os anos de 1996 a 2004, verificou-se que grande parte das pesquisas (70\%) são caracterizadas como estudos de caso.

Gráfico 3 - Método de pesquisa empregado nos artigos

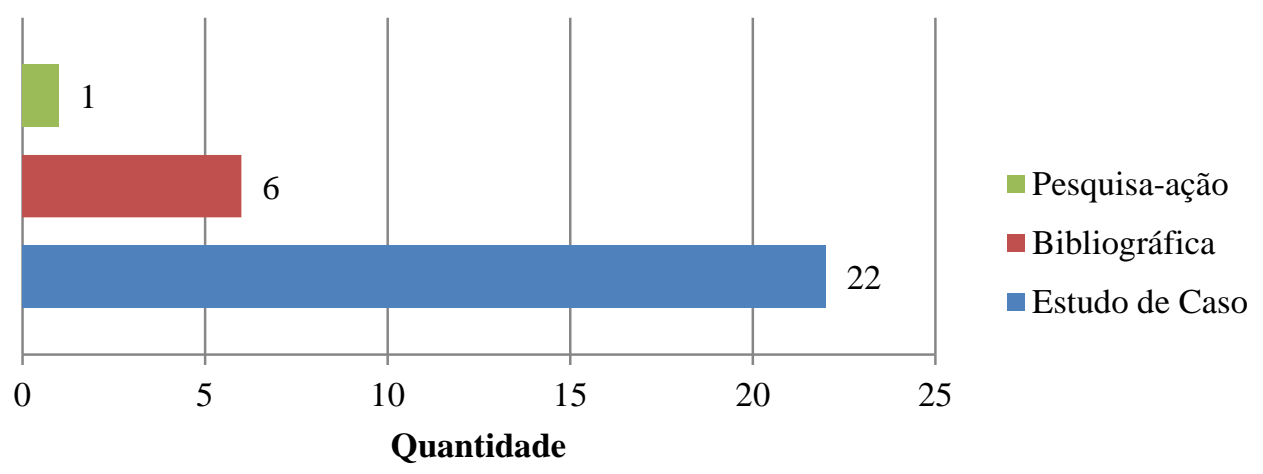

Fonte: Elaborado pelos autores

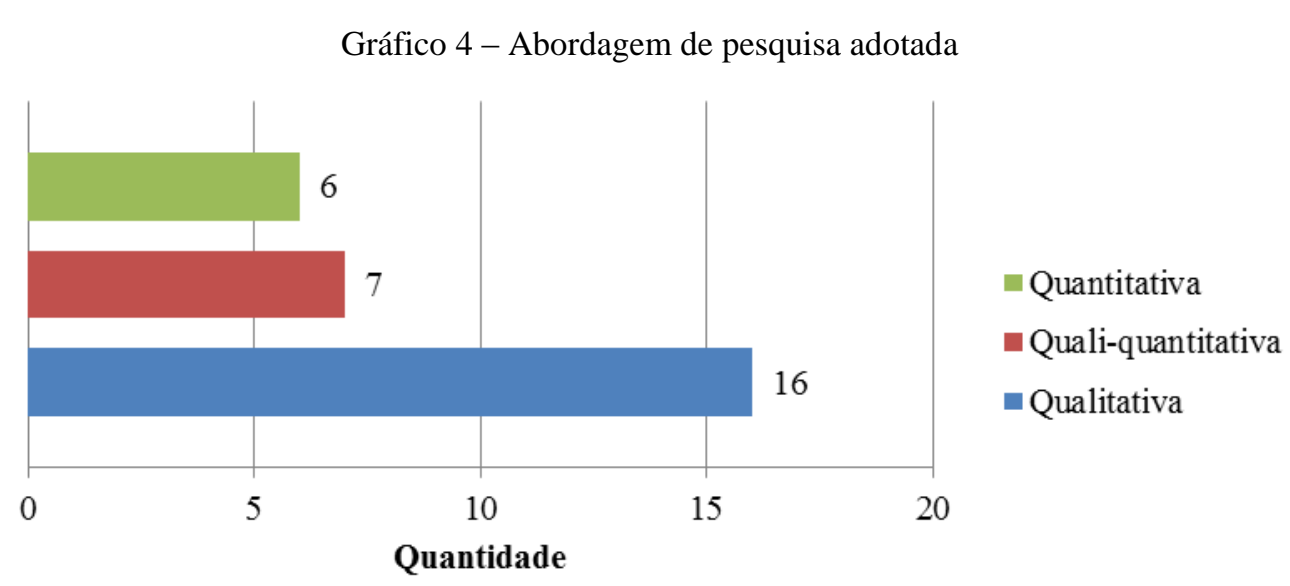

Fonte: Elaborado pelos autores

\subsection{Região e instituição de vínculo dos autores}

No Gráfico 5 pode-se verificar a produção dos artigos por regiões (para tanto foi considerado o estado que a universidade ou instituição em que os autores são filiados). Dessa 
forma, constatou-se que a região Sudeste está à frente das demais regiões em relação ao desenvolvimento de pesquisas sobre APL dentro do contexto da EP. No entanto, as regiões Sul e Nordeste também se destacam em relação às pesquisas realizadas sobre a temática. Nas regiões Centro-Oeste e Norte encontram-se os maiores déficits de pesquisas sobre APL's.

Gráfico 5 - Regiões do país que mais publicaram

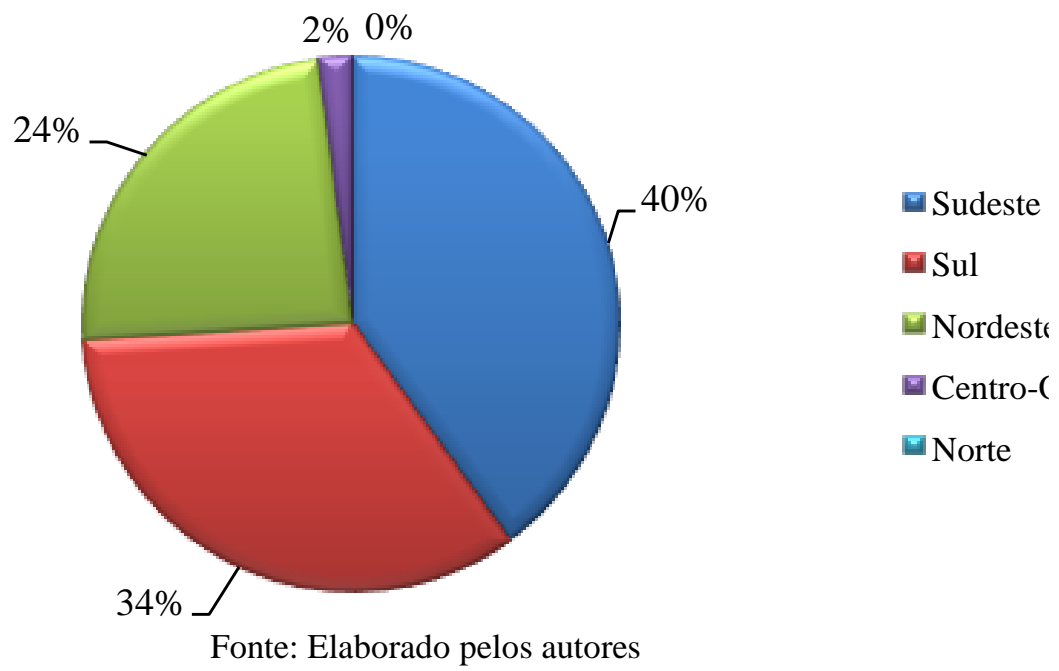

O Gráfico 6 demonstra em detalhes quais foram as instituições que mais publicaram no período que compreende a presente pesquisa. A Universidade que mais se destacou foi a UTFPR (Universidade Tecnológica Federal do Paraná), com sete artigos publicados nos principais periódicos nacionais de Engenharia de Produção. Além desta, outras quatro instituições tiveram destaque, sendo elas UFCG (Universidade Federal de Campina Grande), UFPB (Universidade Federal da Paraíba), UENF (Universidade Estadual do Norte Fluminense) e USP (Universidade de São Paulo). No total foram 33 as instituições nacionais que publicaram sobre a temática APL nos periódicos pesquisados no período que compreendeu a pesquisa.

\subsection{Autores dos artigos}

$\mathrm{Na}$ Tabela 1 podem ser visualizados os autores que mais publicaram nos periódicos analisados. Destacam-se que os pesquisadores Gesinaldo Ataíde Cândido e Luís Maurício Martins de Resende, das instituições UFCG e UTFPR, respectivamente, foram os únicos autores com participação em três ou mais artigos diferentes, o que equivale à apenas 2,6\% dos autores (Tabela 1). 
Gráfico 6 - Instituições do país que mais publicaram

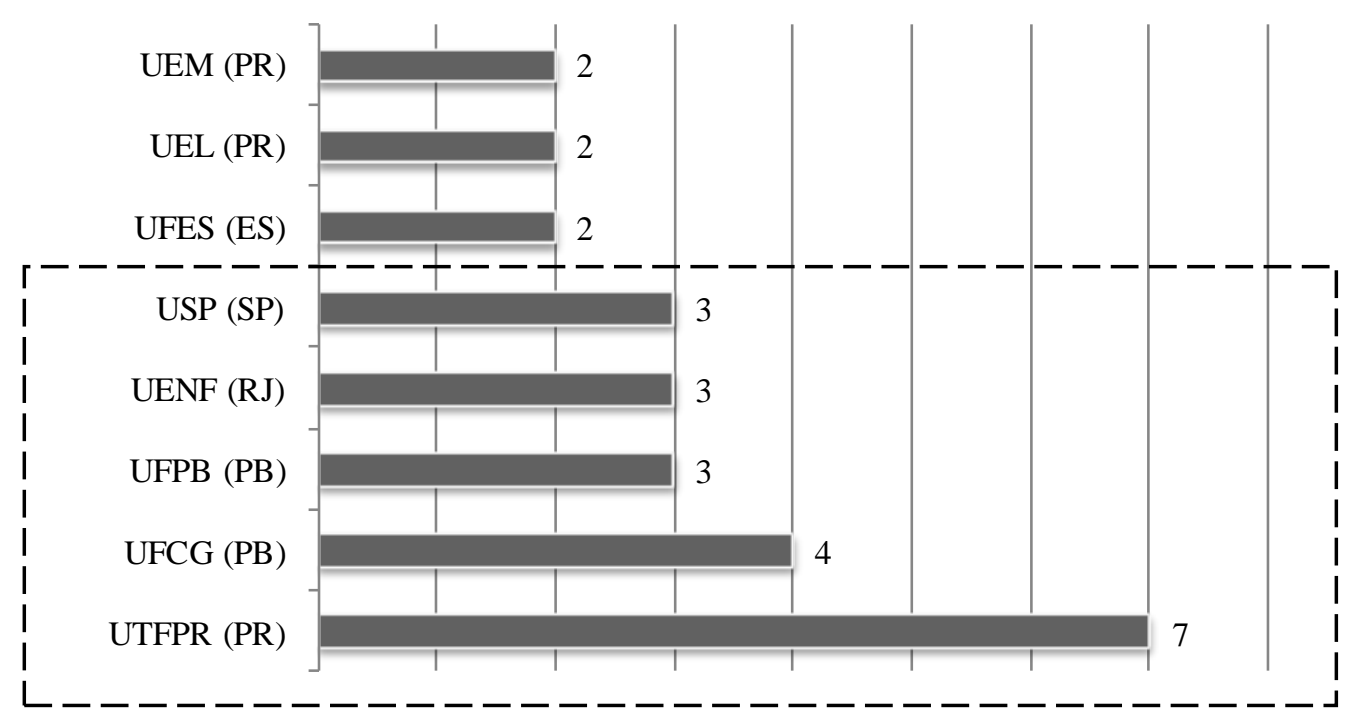

Fonte: Elaborado pelos autores

No total foram identificados 75 autores diferentes nos 29 artigos analisados formando uma média de 2,6 autores por artigo. A maior parte dos autores, mais de 90\%, participou apenas de uma publicação.

Tabela 1 - Pesquisadores por artigo

\begin{tabular}{|c|c|c|c|}
\hline \multicolumn{4}{|c|}{ Autores por artigo } \\
\hline Contribuições & $\mathbf{N}^{\mathbf{0}}$ de Autores & $\%$ & Principais Autores \\
\hline Com 1 artigo & 68 & $90,7 \%$ & - \\
\hline Com 2 artigos & 5 & $6,7 \%$ & $\begin{array}{c}\text { Ana Cecília Feitosa de Vasconcelos; Fabrício Alexandre } \\
\text { Alves Ceranto; José Arica; Rodolfo Reinaldo Petter; } \\
\text { Sebastião Décio Coimbra de Souza }\end{array}$ \\
\hline Com 3 artigos & 1 & $1,3 \%$ & Luis Mauricio Martins de Resende \\
\hline Com 4 artigos & 1 & $1,3 \%$ & Gesinaldo Ataíde Cândido \\
\hline TOTAL & $\mathbf{7 5}$ & $\mathbf{1 0 0 , 0 \%}$ & \\
\hline
\end{tabular}

Fonte: Elaborado pelos autores

\subsection{Abordagem teórica adotada nos artigos}

Por meio da análise dos artigos foi possível identificar as principais temáticas abordadas nas pesquisas, conforme pode ser observado no Gráfico 7. Como pode ser verificado, o tema mais pesquisado nos artigos analisados foi "competitividade" com oito artigos publicados, seguido da sustentabilidade, em que foram identificadas duas temáticas: a sustentabilidade ambiental e a sustentabilidade do APL, totalizando cinco artigos. 
Gráfico 7 - Abordagem teórica adotada nos artigos revisados

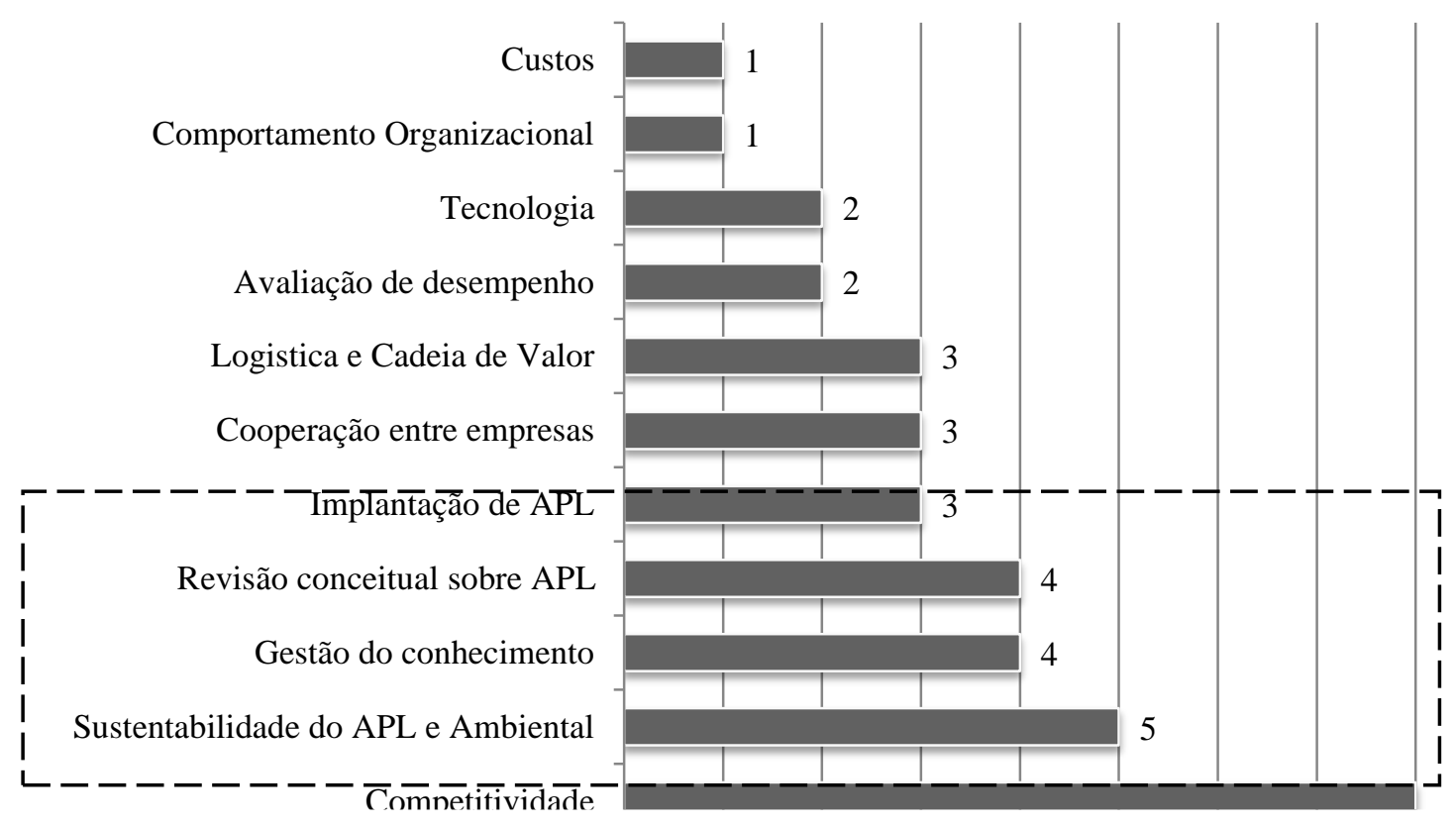

Fonte: Elaborado pelos autores

Convém destacar que os artigos que abordam o tema competitividade têm como principal foco a análise, a apresentação e a avaliação do nível de competitividade dos APL`s, sendo esta temática de extrema relevância, uma vez que são inúmeros os benefícios das aglomerações produtivas, conforme destacado na revisão teórica apresentada anteriormente.

Assim como na seção 4.2, a soma dos artigos no Gráfico 7 (total de 36 artigos), ultrapassa a quantidade de artigos analisados, 29, pois em alguns deles há mais de uma abordagem teórica abordada na pesquisa.

\section{Perspectivas para a Engenharia de Produção}

Ao se relacionar as grandes áreas da Engenharia de Produção definidas pela ABEBRO (2013) com as abordagens teóricas identificadas nos artigos analisados (ver novamente Gráfico 7) pôde-se elaborar o Gráfico 8. O total de artigos apresentados no Gráfico 8 é maior que o total de artigos analisados, por ter artigos com mais de uma abordagem teórica, envolvendo diferentes áreas da Engenharia de Produção.

De acordo com o exposto no Gráfico 8, percebe-se que as pesquisas sobre APL's no período analisado estão concentradas na área de Engenharia Organizacional. Segundo a ABEPRO (2013) esta área concentra um conjunto de conhecimentos relacionados à gestão das organizações, trabalhando com temas que tratam sobre planejamento estratégico e operacional; estratégias de produção, gestão empreendedora; gestão do conhecimento; avaliação de desempenho organizacional, sistemas de informação; e, por fim, arranjos produtivos. A área de Engenharia da Sustentabilidade também tem se destacado nas pesquisas sobre APL's nos periódicos pesquisados. 
Gráfico 8 - Enquadramento dos artigos nas áreas da EP

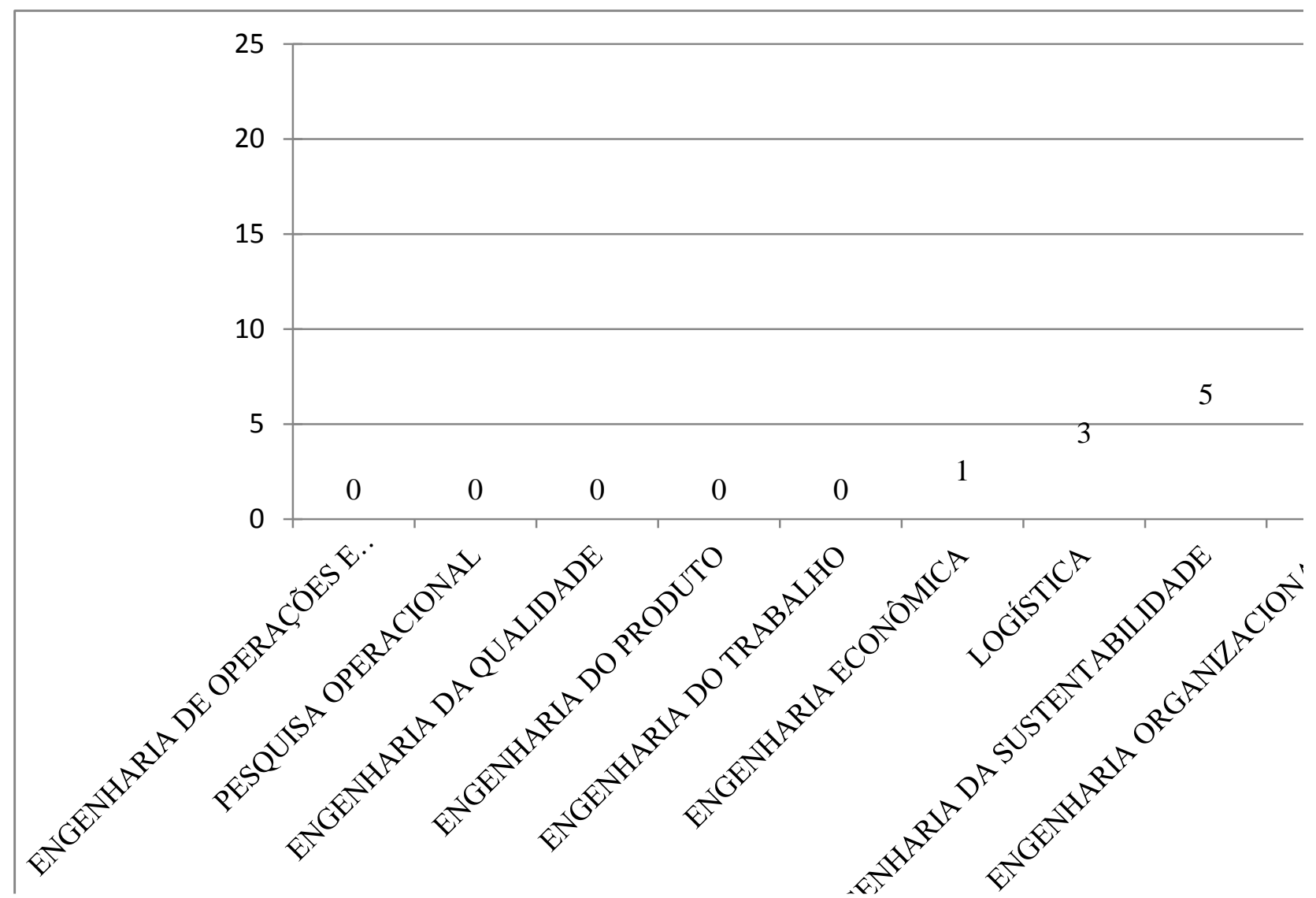

Fonte: Elaborado pelos autores

As demais áreas da Engenharia de Produção são carentes de pesquisas sobre APL's. Por exemplo, na área de Logística foram identificados três artigos que abordaram a temática APL e a área de Engenharia Econômica apenas um artigo. As demais áreas não foram tratadas nos artigos analisados nesta pesquisa.

Convém destacar que as teorias sobre redes empresariais (apresentadas no Quadro 3 revisão teórica) e que consideram alguns fundamentos sobre o processo de cooperação e parceria entre as empresas, como a teoria dos jogos, a teoria do poder de mercado, a teoria dos custos de transação, a teoria das redes sociais, a teoria da visão baseada em recursos, a teoria da gestão do conhecimento e a teoria da aprendizagem organizacional (LAVIE, 2006; VALE; LOPES, 2010; WILK, 2006), podem ser relacionadas com as Áreas da Engenharia de Produção. Por exemplo, a teoria dos custos de transação relaciona-se fortemente com a área de logística e gestão da cadeia de suprimentos; a teoria da visão baseada em recursos também pode ser aplicada na área de Engenharia de Operações e Processos da Produção, assim como na área de Engenharia Organizacional. Dessa forma, percebeu-se nos artigos analisados, que algumas pesquisas relacionaram essas teorias. Destaque para a teoria das redes sociais, com cinco artigos; seguido da teoria dos custos de transação, gestão do conhecimento e aprendizagem organizacional, com três artigos cada uma. 


\section{Conclusões}

O objetivo principal deste artigo foi desenvolver uma análise da produção científica sobre arranjos produtivos locais nos principais periódicos nacionais da área de Engenharia de Produção nos últimos onze anos, apresentando uma perspectiva sobre os estudos feitos e os principais assuntos pesquisados. Dessa forma, o presente trabalho apresentou informações e possibilitou a expansão da ciência acerca do tema Arranjos Produtivos Locais dentro do contexto da Engenharia de Produção.

A pesquisa foi desenvolvida utilizando como base as palavras-chave: "Arranjos Produtivos Locais" ou "Arranjo Produtivo". Em uma pesquisa inicial foram encontrados 93 artigos, dos quais 64 foram descartados de acordo com os critérios de exclusão estabelecidos. Dessa forma, foram analisados 29 artigos com base nos seguintes critérios: evolução das publicações por ano; tipo de APL pesquisado; definições de APL apresentadas; procedimento de pesquisa adotado; local de publicação relacionado à instituição de vínculo dos autores; contribuições por autor; contribuições por periódico; e, abordagem teórica adotada nos artigos. Com base nestas análises obtiveram-se alguns resultados interessantes.

Em relação à evolução das publicações, verificou-se que nos anos de 2002 a 2004 não foi encontrada nenhuma publicação sobre APL. Posteriormente, as pesquisas entraram em uma tendência de crescimento até o ano de 2009 e em seguida começaram a cair, variando de nove artigos no ano de 2009 para apenas dois no ano de 2012. Também foi possível constatar que o principal método de pesquisa adotado nos artigos analisados foi o estudo de caso, caracterizando a pesquisa sobre APL's nos periódicos analisados, em sua grande maioria, como empíricas. Isso demonstra que os estudos sobre APL dentro da área de Engenharia de Produção tem a preocupação de se aplicar conceitos e teorias dentro das empresas que fazem parte do APL.

Quanto às regiões, instituições e periódicos que mais publicaram no período que compreendeu a pesquisa, merece destaque a região Sudeste e a Universidade Tecnológica do Paraná. Os estudos sobre APL nas instituições das regiões norte e centro-oeste é praticamente inexistente, no entanto a região nordeste que tem participação em $24 \%$ dos artigos, tem duas instituições que estão entre as três que mais publicaram. Já em relação aos periódicos que mais publicaram no período analisado, destacam-se a Produção Online e a Revista Gestão Industrial.

Em relação aos autores mais citados no que diz respeito à definição do APL, ressaltam-se em relação aos demais, Cassiolato e Lastres, por serem os coordenadores do glossário da Redesist, que pode ser considerado uma das principais referências para a definição de APL's em função da quantidade de citações nos artigos analisados. 
As principais abordagens teóricas adotadas pelos artigos foram "Competitividade" e "Sustentabilidade do APL e Sustentabilidade Ambiental", as quais somaram 13 artigos dos 29 analisados. Essas abordagens estão contempladas em duas grandes áreas da Engenharia de Produção: Engenharia Organizacional e Engenharia da Sustentabilidade. As demais áreas da Engenharia de Produção praticamente não foram contempladas nos artigos analisados. Dessa forma, sugere-se que sejam desenvolvidas pesquisas sobre APL's que abordem as outras áreas da Engenharia de Produção, tais como: Engenharia de Operações e Processos da Produção; Pesquisa Operacional; Engenharia da Qualidade; Engenharia do Produto; e, Engenharia do Trabalho. Além disso, de uma forma geral, considerando o horizonte de tempo de onze anos e a quantidade de periódicos analisados, a análise fornece evidências da necessidade de se desenvolver mais pesquisas sobre APL's, principalmente relacionadas com Engenharia de Produção.

Convém destacar que as teorias sobre redes empresariais que consideram alguns fundamentos sobre o processo de cooperação e parceria entre as empresas, praticamente não foram contempladas nos artigos analisados. Apenas a teoria das redes sociais, a teoria dos custos de transação, a teoria de gestão do conhecimento e aprendizagem organizacional foram abordadas nos artigos analisados. Entretanto, outras teorias, como por exemplo, a visão baseada nos recursos da firma, poderia ser abordada nas pesquisas que tratam sobre APL segundo a ótica da Engenharia de Produção, pois esta teoria, quando adotada de uma forma estendida, considera que os recursos estratégicos que estão além das fronteiras das firmas podem gerar "quase-rendas específicas de colaboração" ou "quase-rendas relacionais" enfatizando o relacionamento entre empresas interconectadas em redes. Dessa forma, os recursos estratégicos fora dos limites da firma podem ser acessados por outras empresas em função dos relacionamentos cooperativos (SLACK; LEWIS, 2009).

Cabe ressaltar que os dados analisados e interpretados nesse artigo são parciais, uma vez que o trabalho limitou-se aos periódicos nacionais classificados pelo Qualis em Engenharias III, dentro de um determinado período de tempo. Dessa forma, sugere-se que sejam desenvolvidas pesquisas em âmbito internacional nos principais periódicos da área de Engenharia de Produção, para fazer uma análise comparativa das publicações sobre APL's entre o Brasil e o exterior. Entretanto, dada a quantidade de denominações sobre APL's, sugere-se fazer uma pesquisa mais ampla, englobando outras palavras-chave, tais como clusters, redes de negócios, redes de pequenas e médias empresas, redes de cooperação, entre outras denominações. Por fim, a revisão sistemática da literatura sobre APL's permitiu identificar lacunas possíveis de se tornarem futuras pesquisas a respeito do tema dentro do contexto da Engenharia de Produção. 


\begin{abstract}
The aim of this paper is to develop a survey of scientific literature about local production networks in the major national journals in Production Engineering, presenting an overview of the studies and the main issues studied over the last eleven years. The article adopted the approach of systematic review that was used in order to develop a survey of scientific literature about local production networks in seven journals. The choice of journals was due to these being ranked in the CAPES (QUALIS) evaluation system in the field of Engineering III, which includes Production Engineering. The search of the papers used as keywords: "local production networks " or "productive arrangement". In an initial search it was found 93 articles, of which 64 were excluded according with predefined criteria. Then, 29 articles were analyzed according to the following aspects: evolution of publications; type of network, network definitions; research procedure; authors of the articles; region and institution; contributions by author, contributions by journal, and theoretical approach adopted. Through analysis, we conclude that research on this subject is evolving, although the research in most of Production Engineering subjects remains unexplored.
\end{abstract}

Key-words: local production networks; systematic review, national journals.

\title{
Agradecimentos
}

Os autores agradecem ao Conselho Nacional de Desenvolvimento Científico e Tecnológico (CNPq) por ter financiado e possibilitado esta pesquisa.

\section{Referências}

ABEPRO (Org.). Áreas e sub-áreas de Engenharia de Produção. Disponível em: <http://www.abepro.org.br/interna.asp?c=362>. Acesso em: 31 jan. 2013.

AHUJA, G.; SODA, G.; ZAHEER, A. The genesis and dynamics of organizational networks. Organization Science, v. 23, n. 2, p.434-448, 2012. ABEPRO (Org.). Áreas e sub-áreas de Engenharia de Produção. Disponível em: <http://www.abepro.org.br/interna.asp?c=362>. Acesso em: 31 jan. 2013. crossref

AHUJA, G.; SODA, G.; ZAHEER, A. The genesis and dynamics of organizational networks. Organization Science, v. 23, n. 2, p.434-448, 2012.

ALBINO, A. A. et al. Aplicação do modelo analítico da cadeia de valor na análise da estratificação competitiva em um APL. Produção Online, v. 11, n. 1, p.263-287, 2011. crossref

ALCÁCER, J.; ZHAO, M. Local R\&D strategies and multilocation firms: the role of internal linkages. Management Science, v. 58, n. 4, p. 734-753, 2012. cross ref

AMATO NETO, J. Redes de cooperação produtiva e clusters regionais: oportunidades para as pequenas e médias empresas. São Paulo: Atlas, 2000.

ANDERSSON, M.; LÖÖF, H. Agglomeration and productivity: evidence from firm-level data. Annals of Regional Science, v. 46, n. 3, p. 601-620, 2011. crossref

ANDRADE, E. O. et al. Comportamento organizacional de arranjos produtivos locais: um estudo aplicativo no setor de confecções. Sistemas \& Gestão, v. 5, n. 3, p.136-148, 2010.

ARIKAN, A. T.; SCHILLING, M. A. Structure and governance in industrial districts: implications for competitive advantage. Journal of Management Studies, v. 48, n. 4, p.772-803, 2011. crossref

BARROS, R. A. et al. Práticas de sustentabilidade empresarial no APL calçadista de Campina Grande - PB: um estudo de caso. Revista Gestão Industrial, v. 6, n. 1, p.157-177, 2010. 
BORIN, E. C. P. O SEBRAE e os arranjos produtivos locais: o caso de Nova Friburgo/RJ. 2006. 247 f. Tese (Doutorado em Planejamento Urbano e Regional) - Programa de Pós-Graduação em Planejamento Urbano e Regional, UFRJ, Rio de Janeiro, 2006.

BRITO, A. M.; LEITE, M. S. A. Discussão sobre as características dos diferentes arranjos empresariais. In: ENEGEP, 28., 2008. Anais... Rio de Janeiro: ABEPRO, 2008. p. 1-13.

CARDOSO, J. F.; CARDOSO, J. G.; CASAROTTO FILHO, N. A estrutura intelectual de investigação de aglomerações produtivas: um estudo no âmbito da ABEPRO. Produção Online, v. 11, n. 3, p.871-890, 2011. crossref

CARLSON, K. D.; JI, F. X. Citing and building on meta-analytic findings: a review and recommendations. Organizational Research Methods, v. 14, n. 4, p. 696-717, 2011. crossref

CARNEIRO, C. M. B. et al. A redução dos custos no uso de arranjos produtivos locais na gestão competitiva da logística de suprimentos: estudo de caso no APL Leite \& Sol da cadeia produtiva do leite no Estado do Ceará. Produção Online, v. 7, Edição Especial, 2007.

CASAROTTO FILHO, N. Projeto de negócio: estratégias e estudos de viabilidade. São Paulo: Atlas, 2002.

CASSIOLATO, J. E.; LASTRES, H. M. M. Glossário de arranjos e sistemas produtivos e inovativos locais. Rio de Janeiro: Redesist, 2003.

CAVALCANTI, M.; FARAH, O. E. Meio-ambiente e sustentabilidade logística: humanização da produção através de arranjos produtivos locais no Estado de São Paulo. Revista Gestão Industrial, v. 4, n. 1, p.131-147, 2008. cross ref

CAVALCANTI, M.; LIMA, R.; PEREIRA NETO, A. Gestão do conhecimento em arranjos produtivos locais: o caso de Nova Friburgo. Produto \& Produção, v. 8, n. 3, p.25-44, 2005.

CHAI, K.; YAP, C.; WANG, X. Network closure's impact on firms' competitive advantage: the mediating roles of knowledge processes. Journal of Engineering and Technology Management, v. 28, n. 2, p. 2-22, 2011. crossref

CHIOCHETTA, J. C.; HATAKEYAMA, K. Implementação de um APL - arranjo produtivo local: o caso do setor metal mecânico da região sudoeste do Estado do Paraná. Produção Online, v. 7, n. 7, p.58-70, 2007.

CÔRTES, A. M.; ROMANO, C. A.; BARROS JUNIOR, P. A. Instrumentos de apoio à inovação tecnológica no Paraná: disponibilidade e uso nas empresas do arranjo produtivo local (APL) de software de Curitiba. Sistemas \& Gestão, v. 6, n. 4, p.447-462, 2011. crossref

DOMINGUES, R. M.; PAULINO, S. R. Potencial para implantação da produção mais limpa em sistemas locais de produção: o pólo joalheiro de São José do Rio Preto. Gestão \& Produção, v. 16, n. 4, p.691-704, 2009. crossref

FLEURY, A. O que é engenharia de produção? In: BATALHA, M. O. (org.). Introdução à engenharia de produção. Rio de Janeiro: Elsevier, 2008, p. 1-10

GALDÁMEZ, E. V. C.; CARPINETTI, L. C. R.; GEROLAMO, M. C. Proposta de um sistema de avaliação do desempenho para arranjos produtivos locais. Gestão \& Produção, v. 16, n. 1, p.133-151, mar. 2009. cross ref

GEROLAMO, M. C. et al. Clusters e redes de cooperação de pequenas e médias empresas: observatório europeu, caso alemão e contribuições ao caso brasileiro. Gestão \& Produção, v. 15, n. 2, p. 351-365, 2008. crossref

GONÇALVES, A. T. P.; LEITE, M. S. A.; SILVA, R. M. Um estudo preliminar sobre as definições e as diferenças dos principais tipos de arranjos empresariais. Produção Online, v. 12, n. 3, p.827-854, 2012. cross ref

HANSEN, P. B.; OLIVEIRA, L. R. Proposta de modelo para avaliação sistêmica do desempenho competitivo de arranjos produtivos: o caso do arranjo coureiro-calçadista do Vale dos Sinos (RS - Brasil). Produto \& Produção, v. 10, n. 3, p.61-75, 2009.

IACONO, A.; NAGANO, M. S. Uma análise e reflexão sobre os principais instrumentos para o desenvolvimento sustentável dos arranjos produtivos locais no Brasil. Revista Gestão Industrial, v. 3, n. 1, p.37-51, 2007. cross ref

LASTRES, H.; SZAPIRO, M. Novas políticas na era do conhecimento: o foco em arranjos produtivos e inovativos locais. Universidade Federal do Rio de Janeiro, 2003. 
LAVIE, D. The competitive advantage of interconnected firms: an extension of the resource-based view. Academy of Management Review, v. 31, n. 3, p. 638-658, 2006. crossref

LIN, H.-M. et al. How to manage strategic alliances in OEM-based industrial clusters: network embeddedness and formal governance mechanisms. Industrial Marketing Management, v. 41, n. 3, p.449-459, 2012. crossref

MARCHI, J. J.; WITTMANN, M. L. Redes de empresas: uma análise das relações entre fatores sócio-comportamentais e desempenho competitivo. Revista Eletrônica de Administração, v. 14, n. 2, p. 1-28, 2008.

NAKANO, D. Métodos de pesquisa adotados em engenharia de produção e gestão de operações. In.: CAUCHICK MIGUEL, Paulo A. (coord.) Metodologia de pesquisa em engenharia de produção e gestão de operações. Rio de Janeiro: Elsevier; ABEPRO, 2010, p. 63-72.

NASCIMENTO, L. T.; CARDOSO, P. A.; LIMA, E. P. Estudo da competitividade do arranjo produtivo local das empresas de cal da região metropolitana de Curitiba. Revista GEPROS, v. 4, n. 3, p.157-170, 2009.

PAGANI, R. N.; RESENDE, L. M.; MARÇAL, R. F. M. Proposta de aplicação do método PDCA na estruturação de um SPL na região dos Campos Gerais, PR, Brasil. Produção Online, v. 9, n. 2, p.340-360, 2009.

PETTER, R. R.; CERANTO, F. A. A.; RESENDE, L. M. M. As ações de cooperação interfirmas nos arranjos produtivos locais Paranaenses. Produto \& Produção, v. 12, n. 3, p.39-48, 2011 a.

PETTER, R. R.; RESENDE, L. M.; CERANTO, F. A. A. Nível de maturidade de arranjos produtivos locais (APL): um diagnóstico no APL de bonés de Apucarana - PR. Produção Online, v. 11, n. 3, p.803-822, 2011b. crossref

PORTER, M. Vantagem competitiva das nações. Rio de Janeiro: Campus, 1990.

PURCIDONIO, P. M.; FRANCISCO, A. C. Práticas de gestão do conhecimento: um estudo de caso em uma indústria do APL do setor moveleiro de Arapongas. Revista Gestão Industrial, v. 3, n. 4, p.69-80, 2007. crossref

REIS, A. P.; AMATO NETO, J. Aprendizagem por cooperação em rede: práticas de conhecimento em arranjos produtivos locais de software. Produção, v. 22, n. 3, p.345-355, 2012. crossref

SACOMANO NETO, M.; PAULILLO, L. F. de O. Estruturas de governança em arranjos produtivos locais: um estudo comparativo nos arranjos calçadistas e sucroalcooleiro no Estado de São Paulo. Revista de Administração Pública, v. 46 , n. 4 , p. $131-155,2012$. cross ref

SANTOS, A. M. M. M.; GUARNERI, L. S. Características gerais do apoio e arranjos produtivos locais. Revista do BNDES, n. 12, p. 195-204, 2000.

SANTOS, D. T.; BATALHA, M. O. Estratégia de produção em arranjos produtivos cerâmicos: o caso de Pedreira (SP). Produção Online, v. 10, n. 3, p.599-620, 2010.

SANTOS, J. A. et al. Competitividade em arranjos produtivos locais: uma análise do arranjo produtivo local de software da cidade de João Pessoa - PB. Revista Gestão Industrial, v. 5, n. 4, p.42-58, 2009.

SILVA, R. J. A.; SICSÚ, A. B.; CRISÓSTOMO, A. P. Identificação de processos de conhecimento: estudo multicaso em APL de calçados de Campina Grande. Revista Gestão Industrial, v. 5, Edição Especial, p.189-215, 2009.

SILVESTRE, B. S.; DALCOL, P. R. T. Modelos de análise de aglomerados industriais: implicações no estudo do aglomerado de petróleo e gás do norte Fluminense. Revista Gestão Industrial, v. 3, n. 2, p.119-130, 2007. crossref

SLACK, N.; LEWIS, M. Estratégia de operações. Porto Alegre, Bookman, 2009.

SOUZA, L. G. A.; CÂMARA, M. R. G.; ARBEX, M. A. Cooperação entre firmas localizadas em arranjos produtivos locais (APL's): um estudo nas empresas do vestuário de Londrina (PR). Revista GEPROS, v. 1, n. 3, p.89-99, 2006.

SOUZA, S. D. C.; ARICA, J. Mudança tecnológica e estratificação competitiva em um arranjo produtivo do setor ceramista. Produção, v. 16, n. 1, p.88-99, 2006a. crossref

SOUZA, S. D. C.; ARICA, J. Uma análise comparativa entre sistemas de inovação e o diamante de Porter na abordagem de arranjos produtivos locais. Produção, v. 16, n. 1, p.80-87, 2006b. cross ref 
SOUZA, S. M. A.; CÂNDIDO, G. A. Relações entre as formas de governança de arranjos produtivos com a competitividade e o desenvolvimento local sustentável. Revista Gestão Industrial, v. 5, n. 1, p.161-187, 2009.

SUZIGAN, W. (Coord.). Identificação, mapeamento e caracterização estrutural de arranjos produtivos locais no Brasil. Ipea, 2006. 56 p. Disponível em:

<http://www.ipea.gov.br/sites/000/2/estudospesq/apls/Relat_final_IPEA28fev07.pdf>. Acesso em: 20 fev. 2013.

TRANFIELD. D.; DENYER, D.; SMART, P. Towards a methodology for developing evidence-informed management knowledge by means of systematic review. British Journal of Management, v.14. n. 3, p. 207-222, 2003. crossref

VALE, G. M. V.; LOPES, H. E. G. Cooperação e alianças: perspectivas teóricas e suas articulações no contexto do pensamento estratégico. Revista de Administração Contemporânea, v. 14, n. 4, p. 722-737, 2010. cross ref

VIAL et al. Arranjos produtivos locais e cadeias agroalimentares: revisão conceitual. Revista GEPROS, v. 4, n. 3, p. 105-121, 2009.

WILK, E. O. A relação entre estratégias, recursos e performance. 2006. 227f. Tese (Doutorado em Agronegócios) Programa de Pós-Graduação em Agronegócios, UFRGS, Porto Alegre, 2006.

\section{Dados dos autores:}

\section{Nome completo: Cláudia Fabiana Gohr}

Filiação institucional: Universidade Federal da Paraíba

Departamento: Engenharia de Produção

Função ou cargo ocupado: Professora

Endereço completo para correspondência: UFPB - Universidade Federal da Paraíba, Departamento de Engenharia de Produção, Centro de Tecnologia - Campus I, Bloco G, Cidade Universitária

João Pessoa - PB, Brasil, Cx. Postal: 5045, CEP: 58.051-970

Telefones para contato: (83) 3216-7549; (83) 9608-4224

e-mail: claudiagohr@ct.ufpb.br

\section{Nome completo: Rodrigo Araújo de Medeiros}

Filiação institucional: Universidade Federal da Paraíba

Departamento: Engenharia de Produção

Função ou cargo ocupado: Estudante

Endereço completo para correspondência: Av. Monteiro da Franca, no. 1051, apto. 1701, Bairro: Manaíra, João Pessoa - PB, Brasil, CEP: 58.038-320

Telefones para contato: (83) 3512-6810; (83) 8607-5602

e-mail: rodrigoamedeiros@gmail.com

Nome completo: Luciano Costa Santos

Filiação institucional: Universidade Federal da Paraíba 
Departamento: Engenharia de Produção

Função ou cargo ocupado: Professor

Endereço completo para correspondência: UFPB - Universidade Federal da Paraíba, Departamento

de Engenharia de Produção, Centro de Tecnologia - Campus I, Bloco G, Cidade Universitária

João Pessoa - PB, Brasil, Cx. Postal: 5045, CEP: 58.051-970

Telefones para contato: (83) 3216-7685, (83) 9632-6616

e-mail: luciano@ct.ufpb.br

Submetido em: 18/03/2013

Aceito em: 18/12/2014 